\title{
Technical Support for Improving the Licensing Regulatory Base for Selected Facilities Associated with the Front End of the Fuel Cycle
}

Prepared by R. G. Clark, R. E. Schreiber, J. D. Jamison, L. C. Davenport, D. W. Brite

Pacific Northwest Laboratory

Operated by

Battelle Memorial Institute

Prepared for

U.S. Nuclear Regulatory

Commission 


\section{NOTICE}

This report was prepared as an account of work sponsored by an agency of the United States Government. Neither the United States Government nor any agency thereof, or any of their employees, makes any warranty, expressed or implied, or assumes any legal liability or responsibility for any third party's use, or the results of such use, of any information, apparatus product or process disclosed in this report, or represents that its use by such third party would not infringe privately owned rights.

U. S. Nuclear Regulatory Commission Washington, D. C. 20555

Printed copy price: $\$ 6.00$ 
NUREG/CR-2460

PNL-4086

Technical Support for Improving the Licensing Regulatory Base for Selected Facilities Associated with the Front End of the Fuel Cycle

Manuscript Completed: February 1982

Date Published: April 1982

Prepared by

R. G. Clark, R. E. Schreiber, J. D. Jamison, L. C. Davenport, D. W. Brite

Pacific Northwest Laboratory

Richland, WA 99352

Prepared for

Division of Fuel Cycle and Material Safety

Office of Nuclear Material Safety and Safeguards

U.S. Nuclear Regulatory Commission

Washington, D.C. 20555

NRC FIN B2219 



\section{FOREWORD}

This report was prepared by the Pacific Northwest Laboratory (PNL) under contract to the Nuclear Regulatory Commission. The findings, conclusions and recommendations are those of the contractor and are not necessarily endorsed by the NRC. The NRC staff cooperated fully with the PNL staff members who performed the study, making available to them the licensing files, inspection reports and other infomation, and assisting them with arrangements for interviews with licensees. The authors of the report were encouraged to analyze the information in their own way and to make findings, reach conclusions and develop recommendations independently from the NRC staff. 

ABSTRACT

Pacific Northwest Laboratory (PNL) was asked by the NRC 0ffice of Nuclear Material Safety and Safeguards (NMSS) to determine the adequacy of its health, safety and environmental regulatory base as a guide to applicants for licenses to operate $U_{6}{ }_{6}$ conversion facilities and fuel fabrication plants. The regulatory base was defined as the body of documented requirements and guidance to licensees, including laws passed by Congress, Federal Regulations developed by the NRC to implement the laws, license conditions added to each license to deal with special requirements for that specific license, and Regulatory Guides.

The study concentrated on the renewal licensing accomplished in the last few years at five typical facilities, and included analyses of licensing documents and interviews with individuals involved with different aspects of the 1icensing process. Those interviewed included NMSS staff, Inspection and Enforcement (IE) officials, and selected licensees. From the results of the analyses and interviews, the PNL study team concludes that the regulatory base is adequate but should be codified for greater visibility. PNL recommends that NMSS clarify distinctions among legal requirements of the licensee, acceptance criteria employed by NMSS, and guidance used by all. In particular, a preficensing conference among NMSS, IE and each licensee would be a practical means of setting license conditions acceptable to all parties. 

Pacific Northwest Laboratory (PNL) was asked by the NRC Office of Nuclear Material Safety and Safeguards (NMSS) to determine the adequacy of its health, safety and environmental regulatory base as a guide to applicants for licenses to operate $\mathrm{UF}_{6}$ conversion facilities and fuel fabrication plants. The study concentrated on the renewal licensing process accomplished in the last few years at five typical facilities: Kerr-McGee and Allied Chemical for UF ${ }_{6}$ conversion; and Exxon Nuclear, Rockwell International, and Westinghouse for fuel fabrication.

The 1-year study was conducted by interviewing the licensees, Inspection and Enforcement (IE) officials and inspectors, and the staff of the Uranium Fue? Licensing Branch of NMSS. In addition, in-depth analyses were made of the documentation associated with each renewal activity.

The five-person PNL study team concluded that the regulatory base is indeed adequate, but should be codified (a) for greater visibility. Careful distinctions should be made among requirements imposed by law on licensees, acceptance criteria used by NMSS staff in assessing licensability, and guidance used by NMSS staff and their contractors, or intended for use by the licensees applying for renewal.

The principal recommendation of the PNL study is that NMSS could greatly facilitate the renewal licensing process by arranging for pre-licensing conferences among the NMSS Licensing Project Manager, the regional IE fuel facility inspector, and the licensee at each facility. The purpose of the conference would be to resolve outstanding technical issues, establish acceptable license conditions, and review licensee performance during the previous licensing period.

PNL further recommends that the draft Standard Format and Content Guide for Health and Safety Aspects of Fuel Fabrication Plants, with modifications suggested by this study, be expanded to include environmental aspects and extended to apply to UF 6 conversion facilities. Corresponding Standard Review Plans and Branch Technical Positions should also be prepared.

(a) Systematized as a group of rules and guides that are complete, selfconsistent, unambiguous and properly approved. 



\section{CONTENTS}

FOREWORO

ABSTRACT

SUMMARY

INTROOUCTION

CONCLUS IONS

RECOMMENDATIONS

CURRENT STATUS OF LICENSING PROCESS

DESCRIPTION OF REGULATORY BASES

DESCRIPTION OF LICENSING PRACTICES .

INTERVIEWEE COMMENTS ON THE LICENSING PROCESS $\quad \cdot \quad \cdot \quad \cdot \quad \cdot \quad \cdot 25$

COMMENTS BY NMSS MANAGEMENT AND STAFF ON THE LICENSING PROCESS • 25

COMMENTS BY IE HEADQUARTERS AND REgIONAL OFFICES • • • . $\quad 27$

Comments Regarding the Regulatory Base . . . . . 27

Problems of Existing Licensing Process . . . . . . 29

NRC Staff Capabilities and Interactions . . . . . . 29

Other Comments . . . . . . . . . . . . 30

COMMENTS BY LICENSEES $. \quad . \quad$. $\quad$ • . . . . . . . 30

Health and Safety Related Issues . . . . . . 31

Environmentally Related Issues . . . . . . 31

Comments on the Regulatory Base . . . . . . . . 31

Comments by Licensees on NRC Staff Capabilities . . . 34

Impact of Interactions of NRC with Other Agencies . . . 35

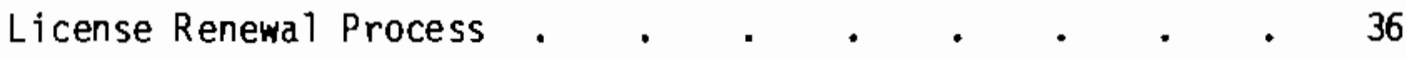

General Critique of Current NRC Licensing Process . . . 38 
Other Comments . . . . . . . . . . . . 39

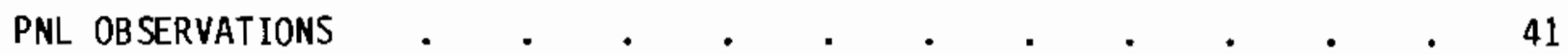

ENFORCEABILITY OF THE REGULATORY BASE $\quad$ • . . . . . 41

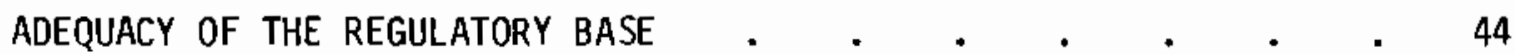

EFFECT OF CHANGES IN THE LICENSING PROCESS $. \quad . \quad . \quad . \quad$. 46

QUESTION-AND-ANSWER PROCESS IN LICENSING RENEWALS . . . . . 48

Relation of Question-and-Answer Process to Safety
Evaluation Report (SER)--The Westinghouse Case . . . 48

Question-and-Answer Process Relative to SER--The Rockwe 11
International Case . $. . \quad . \quad . \quad . \quad . \quad 50$

Comments on the Westinghouse and Rockwell Renewals . $\quad 53$

ROLE OF THE IE OFFICE IN THE LICENSE RENEWAL PROCESS • • • • • $\quad$ • 54

APPENDIX A - LICENSEE AND RC PERSONNEL CONTACTED . . . • . . . A.I

APPENDIX B - GUIDANCE AND CRITERIA USED BY LICENSING PROJECT MANAGERS - B.1

APPENDIX C - COMMENTS ON DRAFT REGULATORY GUIDE, TASK FP 716-4,
DIV. 3, oct. $1980 \quad . \quad . \quad . \quad$. 19.1

APPENDIX D - QUESTIONS AND COMMENTS ON CONSOLIDATED RENEWAL APPLICATION, WESTINGHOUSE ELECTRIC CORPORATION, COLUMBIA, S.C., DOCKET NO. 70-1151, DECEMBER 30, 1976 . D.1 


\section{INTRODUCTION}

The Office of Nuclear Material Safety and Safeguards (NMSS), a component of the Nuclear Regulatory Commission (NRC), is currently seeking to upgrade the health and safety and environmental aspects of the licensing and license renewal procedures for uranium hexafluoride $\left(U F_{6}\right)$ production plants and uranium fuel fabrication and processing plants. As part of the upgrading process, MMSS asked Pacific Northwest Laboratory (PNL) to provide technical support in order to:

1. determine the adequacy of the regulatory base in guiding an applicant on the correlation between the base and the acceptance criteria used by NRC

2. identify where improvements in the technical reviews may be needed as well as alternatives for implementing improvements

3. obtain a data base to better enable the NRC to reconmend areas for regulatory improvements.

To meet these objectives, NRC asked PNL to conduct an in-depth review of current health, safety and environmental licensing, the regulatory process and the regulatory base, and to concentrate on certain recent license renewals with special attention given to the question-and-answer exchange. In addition to studying the documentation, the views and suggestions of those involved in the process were to be solicited.

Besides NMSS, the PNL study team interviewed personnel from the NRC Office of Inspection and Enforcement (IE) headquarters and regions; NRC Office of Standards Development (SD); and selected licensees (Allied Chemical, KerrMcGee, Rockwe1l International, Exxon Nuclear, and Westinghouse Electric). During the interviews, the following questions were asked of each licensee:

- What are your general perceptions of the renewal licensing process?

- Is the available guidance from NMSS adequate for preparing licensing submittals? 
- Do you see a clear correlation between the regulatory base requirements and the acceptance criteria used by ARC in evaluating submittals?

- Will the proposed Standard Format and Content Guide for renewal submittals improve or impede the licensing process?

- Should the license renewal period of 5 years be changed?

- How would it impact your (1icensees') operations if 10 CFR part 70 Ticensing tended toward the detail required of part 50 iicensees (e.g. technical specifications, approval of procedures)?

- What is your relationship with IE?

These questions were somewhat modified when discussed with staff in regional offices. In some instances, extra information or opinions were offered by licensees or IE. NMSS had asked interviewees to be candid.

This report contains the results of the review and interviews, along with PNL observations and recommendations. Appendix A provides a list of all participants. The other Appendices $(B-0)$ contain guidance and criteria used by Licensing Project Managers, comments on the Standard Format and Content Guide, and representative questions and comments on a consolidated renewal application. 
CONCLUSIONS

The following text gives PNL's conclusions on several facets of the licensing process:

1. The primary conclusion of this study is that the renewal licensing process works. The stability of the industry and the competence of NRC staff, both NMSS and IE, combine in an effective way. However several months from now the picture may change if the nuclear economy steps up and the NMSS staff has to cope with an increased work load.

2. A substantial body of licensing precedents is available to guide licensees in preparing renewal submittals. Licensees can take advantage of their own experience and that of others in the industry to update documentation submitted in support of their renewal applications. In general, this source of licensing guidance has been more useful than the regulatory guides and other literature offered as guidance by NMSS. Many questions have also been handled by informal conversation between licensees and their Licensing Project Managers (LPMs). This practice has frequently led to misinterpreted oral agreements and the need for an extensive round of questions by the LPM on the submittal.

3. A good working arrangement exists among the LPMs, the IE inspectors, and the Ticensees. In order to overcome the difficulties associated with the oral agreements mentioned above, this good working relationship among the principals could be better utilized by conducting a pre-licensing conference. The intent of the meeting would be to discuss possible changes in the license and to establish acceptable license conditions. After the meeting, NMSS would issue a letter to the licensee documenting the license conditions that were agreed to and should be written into the submittal. This procedure should greatly reduce the question-and-answer exchange. 
4 The use of contractor personnel to assist in the preparation of environmental assessments and health/safety evaluations is a good augmentation of NMSS staff capabilities. Care must be taken, however, not to involve contractor personnel informally in the licensing process. Asking contractors to explain licensing criteria(a) (such as where to sample for ground water contamination) to licensees places an unfair burden on the contractor and tends to diffuse responsibility for licensing decisions.

5. A clear legal distinction exists between requirements the licensee must meet and acceptance criteria used by the staff. However, there is some confusion among licensees over what is a licensing requirement and what is an acceptance criterion. NRC legal counsel, in expressing concern over "quasi requirements," has provided a workable definition of a requirement. Licensing requirements should be directly traceable to a responsible authority, (b) and are of the form "the neutron multiplication factor, $k$, shall not exceed 0.95 , errors included, in any plant equipment or facility." An acceptance criterion, on the other hand, will refer to a calculational technique for determining $k$ or refer to an ANSI standard or Regulatory Guide--none of which should ever be called a requirement. Such criteria are clearly negotiable but the requirement is not.

6. There is no demand from any quarter for substantial changes in the regulations, but there is a need to clean up a certain looseness. For example, a Regulatory Guide is made a part of the regulations in 10 CFR 20. This and certain de facto requirements by NMSS need to be reexamined during the part 20 and part 70 reviews now under way. Care must be taken not to interpret the licensee's apparent acceptance of the present regulations as approval of them. The licensees are fearful of change because they see an operant philosophy of regulation that "more is better - especially in the environmental field."

(a) See page $0.18, Q / A \# 85$.

(b) Further discussion of the issue of "requirements" is found in the section, PNL Observations - Adequacy of the Regulatory Base. 
Two examples were found to illustrate the fallacy of this philosophy. The first involved a monitoring program for tritium in liquid effluent when the only tritium on plant was in a few foils and could never have come in contact with liquids. This license condition was actually imposed. The second involved an attempt to impose monitoring of ground water for coliform in addition to monitoring requirements and coliform limits on the only effluent stream from the sewage treatment plant. The licensee successfully resisted this action. In neither example was a mechanism for cause-and-effect even considered, yet the licensees were put in financial jeopardy by requirements on situations over which they had no control. NMSS should not allow these situations to become part of the requirements they impose. Whether they come from other agencies as requirements or as requests for data, NMSS should filter these remarks and present them to licensees in the proper light.

7. The staff positions with regard to environmental issues are quite consistent from one licensee to another. However, some of the elements of the regulatory base have not been formally reviewed and approved by responsible authority. (a) If these documents are to be effective and stand up to challenge, they should be promulgated as Regulatory Guides, Standard Review Plans, or as Branch Technical Positions.

8. NMSS policy and practice needs strengthening in the following areas:

a. Acceptance criteria promptly documented and provided to licensees in the proper form.

b. Dependable schedules set for renewal licensing.

c. The legal basis for action firmly established for use by the Licensing and Environmental Project Managers.

d. NMSS taking the lead in organizing pre-licensing conferences to resolve outstanding issues.

(a) Discussion of these documents is found in the Description of Licensing Practices. 



\section{RECOMMENDATIONS}

The PNL study team has developed eleven recommendations to enhance the health, safety and environmental licensing process for fuel fabrication and $\mathrm{UF}_{6}$ conversion facilities. The study team views items 1,2 and 3 as the most significant and recormends that their implementation be given highest priority; items 4-11 are considered to be of approximately equal significance. These recommendations are:

1. NMSS should schedule a pre-licensing conference prior to the start of each license renewal action. This conference of the Licensing Project Manager, the Fuel Facility Inspector, and the licensee would enhance the quality of the license submittal, greatly reduce the need for a question-and-answer exchange, and provide for the constructive feedback of facility inspection and performance measurement results into the renewal process. Specifically, the conference should be planned to:

a. resolve outstanding technical issues

b. establish license conditions that are acceptable to all parties

c. examine the impact (implementation time and cost) of recent rules, orders and decisions of the NRC, along with a walk-through review and discussion of recent physical and procedural changes at the facility

d. set a tentative schedule for the renewal licensing activities

e. review the deficiencies reported by IE during the previous licensing period

f. consider the inspectability of proposed license conditions.

After the conference, NMSS should formally promulgate the license conditions to be incorporated into the license submittal. Those licensees who rate high in the Systematic Appraisal of Licensee Performance (SALP) can be rewarded with a broader license containing less specific license conditions and giving the licensee more latitude in making changes in operations without obtaining prior NRC approval. At the same time, operations in which problems have been 
evident may require uniquely detailed controls. The selective licensing process will provide the necessary flexibility to the Licensing Project Manager while making visible the regulatory control being exercised.

2. In all dealings with licensees, NMSS should clearly distinguish between requirements imposed via the various legal avenues and acceptance criteria used by NMSS staff in assessing the licensing submittals. In addition, NMSS should clearly state, in Branch Technical Positions or in Regulatory Guides, the role of each of various forms of guidance in use by licensees, by NMSS staff, and by contractors performing supportive evaluations.

3. NMSS shouTd press for issuance of the Standard Format and Content Guide for Health and Safety Aspects of Uranium Fuel Fabrication $\mathrm{Pl}$ ants as modified by the comments in Appendix $\mathrm{C}$ to this report. (a) A parallel guide for environmental aspects is also much needed, not only for fuel fabrication plants but for $\mathrm{UF}_{6}$ conversion facilities as well. The preparation of associated Standard Review Plans should begin at the same time.

As the effort to provide quidance proceeds, the need to codify all materials used in licensing and to develop Branch Technical Positions will be apparent. Great care should be taken in delegating the preparation of such guidance documents to other agencies, such as contractors; judgment as to the relative importance of the material can only be made by NMSS itself. The first and most important task will be to extract from recent Safety Evaluation Reports the fundamental requirements and criteria of licensing:

a. Requirements - do they currently have legal foundation, or should they be considered for inclusion in the upcoming revisions of 10 CFR 20 and 10 CFR 70 ?

(a) A similar guide for $U_{6}$ conversion is of lower priority; the health/ safety problems are generally less severe with non-enriched uranium and there are currently only two licensees in this category who would use such a guide. 
b. Criteria - are they already clearly delineated (as in Regulatory Guides), or should they be submitted for public review?

c. Guidance - is it clearly identified, readily available to licensees, and in referenceable form, or should it be codified and issued as formal reports and configuration-controlled methodologies such as computer codes?

It will be evident to NMSS management that organizing the licensing material in this manner will not only be of great use to licensees and NMSS contractors, but will serve to clarify the legal authority of Licensing Project Managers, as well as provide a training tool for continuity within NMSS.

Other tasks, which are not as urgent, are described below:

4. NMSS should change the arbitrary period of 5 years between renewals. The renewal period for any given licensee should be flexible and be based on factors such as the seriousness of deficiencies found during inspections; frequency of requests for amendments; and plant expansion or change in throughput. At least 1 year's notice should be given to the 1 icensee when NMSS decides whether or not to opt for renewal. This has the effect of requiring an annual decision on the need for license renewal based on an assessment of licensee performance.

5. NMSS should ensure that Inspection and Enforcement is given ample time to review and comment on the proposed license.

6. NMSS should set de minimis levels for disposal of low-enriched uranium contaminated scrap and wastes. This specific deficiency in the regulatory base forces licensees to treat large amounts of very lowlevel material as radioactive waste simply because the contained uranium is enriched.

7. NMSS should allow the license to be revised without review by accepting change pages for non-controversial items such as organization 
charts, emergency contacts, corrected charts and figures, and other material as the opportunity arises. This activity should be encouraged to keep the license viable.

8. Whenever possible, NMSS should involve the industry in review of pre7 iminary drafts of proposed regulations. The industry feels strongly that regulators become inflexible after pride of authorship asserts itself in the Federal Register.

9. To assist in maintaining schedules, MMSS should discourage a licensee from requesting amendments while his license renewal is in progress. Amendments initiated by the licensee should be confined to emergency measures, such as unanticipated changes to comply with industry-wide orders.

10. NMSS should give consideration to hosting general meetings of the industry to discuss common problems and opportunities, if the industry sees an advantage in this type of meeting.

11. NMSS management should caution the Licensing Project Managers against accepting as self-imposed license conditions, data or promises of data from the licensees that go beyond the regulatory requirements. This will protect the LPM from being compromised by the goodwill which the licensee feels he is generating. It is not only in the interest of fairness that requirements should be dispensed with an even hand, it is in the best interest of the industry and the agency that controls be administered as broadly as possible. In every area of regulation, including environmental protection, one should work to the lowest acceptable common denominator. Until proven otherwise, licensing precedent is that common denominator. 


\section{CURRENT STATUS OF LICENSING PROCESS}

The NRC uses Title 10 of the Code of Federal Regulations, Parts 40 and 70 , as the principal basis for licensing fuel cycle facilities. Secondary bases are Regulatory Guides and Branch Technical Positions. Regulatory Guides are issued: 1) to describe practices and alternative methods that are acceptable to the regulatory staff in complying with $\mathrm{NRC}$ regulations and 2) to provide guidance to the applicant for complying with regulations. Since Regulatory Guides are not substitutes for regulations, compliance is not mandatory. Branch Technical Positions are guidelines which convey the branch's opinion on particular issues. Although Branch Technical Positions may address policy issues, they represent only branch level viewpoints. Nevertheless, they are useful in assuring that operations are conducted safely in the absence of specific regulatory requirements and may sometimes be imposed as license conditions. License conditions are the enforceable, inspectable aspects of a specific license which are imposed as a result of the review process.

\section{DESCRIPTION OF REGULATORY BASES}

The regulatory bases are the documents used by NMSS in its review of license applications from applicants operating or intending to operate UF 6 or fuel fabrication facilities. The PNL study team effort has been concentrated on the license renewal process (Figure 1), but the bases for initial licensing are essentially the same.

The bases have changed significantly over the last several years, and the license renewa? process for the relatively few facilities in this category has been staggered over that time. Each facility has evolved at a different rate and has unique characteristics, so few statistical generalizations are possible regarding the license renewal process. Accordingly, the study team sampled the renewal process by examining selected facilities that were thought to cover the full range of variety. The team studied the most recent renewal process, which in each case was initiated in or after 1975. 



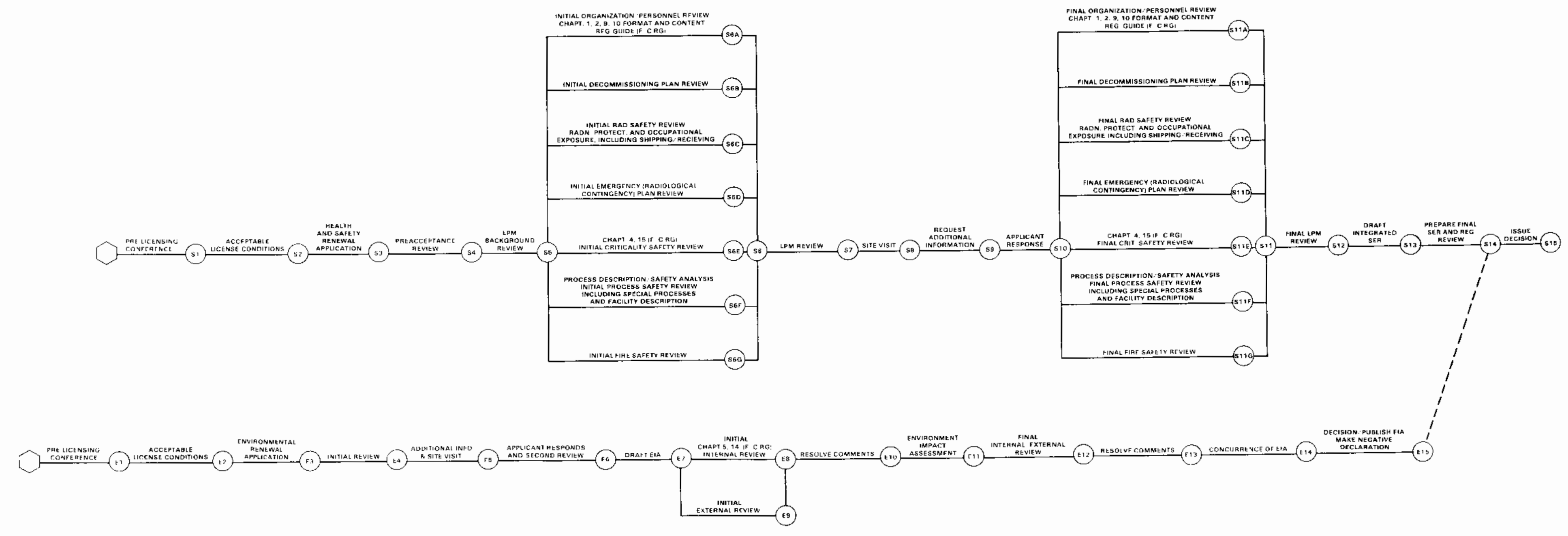

FIGURE 1. NMSS Fuel Cycle Facility License Renewal Process 
Because of the evolutionary nature of renewal licensing, the data were generalized into a composite process in Figure 1 which reflects current practice, and recommended additions. Table 1 gives the documentation used or created at each step in the review process.

Most, but not al1, of the documents cited are paragraphs in the Code of Federal Regulations (CFR). NRC legal counsel has pointed out that documents that are neither regulations nor orders do not have the force of law; they cannot be made requirements. Yet, many of the non-CFR references cited in Table 1 contain criteria used to estabiish licensability, giving them the effect of legal requirements. This subject is treated in greater detail in the observations section of this report.

\section{DESCRIPTION OF LICENSING PRACTICES}

The licensing procedures involved in this study may be conveniently divided into health and safety matters and environmental aspects. Several licensing practices for the time frame covered were not guided by the Standard Format and Content Guide published in draft form October 1980. Consequentiy, several of the licensees developed their own formats and used Regulatory Guides and other documents as guidance in specific areas. The license contains the license conditions (a) agreed to during renewal.

Health and safety aspects of renewal licensing have been largely handled within NMSS. Staff capabilities are excellent in these areas, and the amount of work associated with health and safety has been small enough that external assistance has not been required.

The environmental review, on the other hand, is a more elaborate process requiring outside contractor assistance even though staff capability in this area is also excellent. Furthermore, most concerns are raised in this area, both by 7 icensee and reviewer.

(a) License conditions are all the conditions the Ticensee has initially committed to abide by plus those imposed by NMSS as a result of the review. 


\section{TABLE 1. Regulatory Base Used in the Health and Safety and Environmental License Renewal}

Process Described in Figure 1

Acceptable license conditions

\section{Renewal Appitication}

Pre-acceptance Review

LPM Backgraund Review

Initid Organization and Personnel Review

Initial Decommissioning $P 1$ an Review

Initial Radiation Safety Revier

\section{Functions}

a. resolve putstanding technical issues

. establish non-negotiable license conditions

c. examine the impact (implementation time and cost) of recent rules, orders and decis ions of the NRC, along with a ralk-through and discussion of recent physical and procedural changes at the

d. set a tentative schedule for the renewal licensing activities,

reving deficiencies reported

consider

consider the inspectability of

set what NMS wants to see in

license submittal

Licensee prepares and submits icense renewal application

Staff exmines submittal for completeness

Examination of record of licensee for comparison with renewal application

Same

Same

Examination for changes since initial license issue or previous renewal. Staff calculations as needed.
Documentation, Utilized or Created

Previous license; other documentation as needed

Acceptable license conditions documented in letter by NMSS to licensee.

10 CFR 70.33; Standard Fonmat and Content for the Heal th and Safety Section of the Reneral Application for Uraniun Fuel Fabrication Plants

10 CFR $70.21,10$ CFR $70.22,10$ CFR 70.33, ANSI N1.1-1976 and 10 CFR 70 definitions, RG 10.1, 10 CFR 20 App. B, Tables I, II, 10 CFR 20.203, 5tandard Format: Intro, Chapter 1, 2, 3

IE reports, LERs, License history, unresolved issues, Pending ficense anendments, 10 CFR 70.52, 10 CFR 71 , shipping center cert of compliance, 10 CFR 10.790. 10 CFR 150.36, RG 5.57, RG 7.3, RG 7.4

Standard Format : intro, Chapter 1, 2, 9, 10, 11 , RG 10.1, 10 CFR 21

10 CFR 70, 42 FR 10370 (March 13, 1978), NUREG/CR-1266

Previous license submittal; Standard Format

Guide: Chapter 12, 13; MIOSH Cert. Pers. Protect. Equip. List; NUREG 0436 Attach A; NUREG 0041 , ORO 651,

10 CFR 20.304, 10 CFR $71.11,10$ CFR 71.12, 49 CFR 173.396,

49 CFR 173.389 , ANSI/N $16.4,10$ CFR 20.103, 10 CFR 20.405,

10 CFR 70.2?, 10 CFR 20.106, 10 CFR 19.13, 10 CFR 20.202,

10 CFR 71 , RG 8.15 , RG 8.8, RG 8.11, RG 8.24, RG 8.9, RG 8.10 , RG 1.86 , RG 8.4, RG 8.7 
TABLE 1. (contd)

Step

\section{0}

Initial Emergency (Radiologica Review

Initial Criticality Safety Review

Site visit

Request Additional Information

Applicant response

S11A Final Organization and Personnel Review

511B Final Decommissioning Plan Review

S11C Final Radiation Safety Review

\$110 Final Emergency Plan Review

S11E Final Criticality Safety Review

S1lF Final Process Safety Review

S11G Final Fire Safety Revier

s11 Completion of Final Review

Sane as above
Some
Same
Same
-
Examination of proposed License
Conditions
For major licensing action, staff
reviews include a preliminary
yisit to the site, usually with
IE representative

Question-and-answer exchange with licensee; may take several iterations; license conditions resulting from the exchange, and other staff ult imately imposes unresolved issues as

\section{Same}

5 ame as above

Final calculations and assessment by 5 taff

Final assessment by staff

Final calculations and assessment by staff

Some as above

Final Assessment by staff

Same

Same

Records become basis for SER

Same as above

Same

Same

Same 


\section{TABLE 1. (contd)}

Step

S12

$\$ 13$

$\$ 14$

$\$ 15$

E1

Issue Decision

Pre-licensing Conference

Acceptable license conditions

E3

Renewal Application (Environmental Report)

\section{Departmental Review to assure}

completeness

As stated, IE comments are

incorporated

As stated

Issue formal licerse

a. resolve outstanding technical

b. issues conditions

. examine the impact (implement

ation time and cost) of recent rules, orders and decisions of the ARC, along discussion of recent physical and procedural changes at the facility

d. Set a tentative schedule for the renewal licensing activities

e. review deficiencies reported during the previous licensing period

$f$. consider the inspectability of proposed license conditions

Set what MMSS wants to see in license submittal

Licensee prepares and submits Environmental Report in support of his application for license renewa

\section{Documentation, Utilized or Created}

Internal memo

Draft SER and comments

Final SER and reg review

Form NRC-374 materials license

Previous 1 icense; other documentation as needed

Acceptable license conditions documented in letter by NHSS to licensee.

10CFR 53.40 - Basic requirement for ER for part $40 \leqslant 70$ 1OCFR 51.20 - renewals

Precedents - recent submittals which have been favorably received by the staff

"Interim Guide Lines for preparing Environmental Information for Nuclear Facilities," draft document dated February 1975

Regulatory Guide 1.109 - Dose Model

Regulatory Guide 1.111 - Atmospheric disperison of routine releases 


\section{TABLE 1. (contd)}

Step

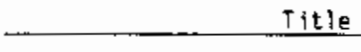

$\varepsilon 4$

E5

Request additional information and conduct site visit

Applicant Responds and Second Review
Pre-acceptance review of $E R$
Functions

ER to determine project manager reviews warranted (b) if if full revie are met, (c) if requirements of

applicable executive orders pertain-

ing to the enviroment are addressed,

(d) history of compliance with

effluent 1 imits/permits
Documentation Utilized or Created

Draft Regulatory Guide on dose models for uranium milling effluents (RHBO2-4)

"Checklist for Contents of Environmental Report for Fue Fabrication Plant," draft document dated January 1974

Regu?atory Guides 1.111, 1.109, Draft RG (Project RG $802-4)$ - Dispersion and dose models

4OCFR 190 - Criteria for offsite dose to maximum indivi dual

ICRP Committee 2, Task Group Lung Mode 1 ICRP 19, Metabolism of compounds of Pu and other actinides

8NH-B - 389 Computer code DACRIN for calculating Organ Doses from Acute or Chronic radionuclide Inhalation

NUREG/CR 0553. ANL/ES - 72 - UDAD code for Uranium Dispersion and Dosimetry

Executive orders on Farmland Preservation. Flood Plan Management, Preservation of $\mathrm{Historical/Archeological}$ 5 ites, Rare and Endangered species

Those listed for E? plus

Environmental project manager,

contractor reviewers and IE inspector

request for further infortions/

applicant

IE inspection reports

EPA/state effluent permit conditions and limits

Applicant submits additional

information and answers to questions

as requested

Oraft Environmental Impact Assessment (EIA) Contractor prepares a oraft of his
Applicant Response

10CFR $51.7-B$ asic requirement for $E I A$ and negative declaration.

40CFR 190-Individual dose criteria

Natural background dose to population, de facto criteria for assessment of population dose from licensee facility

State or Federal air quality guides for specific pollutants 
TABLE 1. (contd)

Step

Title

E8

Initial Internal Review

E9 Initial External Review

$\cong$

E10 Resolve Comments

Ell Envirorment Impact Assessment

E12 Internal/External Reviem of Final EIA

E13 Resolve comments

E14 Concurrence of EIA

E15 Publish EIA/make negative declaration precedents, and current regulatory
Functions Review of Draft EIA by staff
evaluation of contractor finding in evaluation of contractor finding philosophy

Review of Draft EIA by other state and federal agencies with cognizance over aspects of the licensee operation.

Coments from internal and external reviewers resolved/incorporated by contractor. Final ElA prepared.

Staff and External agencies review the final EIA.

Contractor resoives any comments on final EIA.

Staff concurs in contractor

findings of documented in finat EIA.

Finding of "No significant impact is just if ied by ElA, federa register negative declaration made.

Recommendations for Enviromental

conditions to be included in rene-ed

ijcense are iriade to ifcensing project manager

Document ation Ut illized or Created

State or Federal water quality regulation for specific pollutants

Ambient air and water quality in vicinity of the facility, de facto criteria for as sessment of degradation of air or water quality due to licensee activities

Average and minimum flows for streams in vicinity of licensee facility, used in conjunction with above in licensee $f a c i l i t y$ due to addition of pollutants from

Groundwater quality, geohydrology of licensee site; actual or potentral impact of licensed operation on quality of the groundwater

Aesthetics of the facility surroundings provides bases for evaluation of licensee facility's visual impacts more $\mathrm{mr}$ em/yr or more to nearest resident staff require nations on effluent to refine the $40 C F R$ 190 dose determination

State and federal agency rules, permit requirements and executive orders relating to their specif ic area of responsibility; entirely dependent on which agencies show an interest in the proceed ing

Final EIA

FR Notice

\section{Memo}

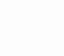


Licensees have been preparing environmental submittals in support of their renewal applications on the basis of several types of official and nonofficial guidance. Perhaps the most useful, from the licensees' point of view, have been the precedents that were established in the course of the earlier licensing actions. The licensee reviews what other licensees have submitted recently, evaluates the staff response to those submittals, and forms a judgment on what to include in an environmental information report. The only documentary guidance provided to the Ticensee appears to be a preliminary draft document entitled "Interim Guidelines for Preparing Environmental Information for Nuclear Facilities," dated February 1975. However, these guidelines do not appear to have been issued in any "official" form or approved. Whether official or not, the document is in use and is provided to applicants who inquire about the content requirements for environmental submittals.

Licensees are also directed (orally) to use various Regulatory Guides and draft documents which contain acceptable models and methods for evaluating environmental impacts. Examples are Regulatory Guide 1.111 (atmospheric dispersion of routine releases), Regulatory Guide 1.109 (dose model), and the draft Regulatory Guide on dose models for uranium milling effluents.

When the environmental submittal is received by NMSS, the Environmental Project Manager (EPM) performs a pre-acceptance review to determine if the report is complete enough to warrant a full detailed review and evaluation. The "Checklist for Contents of Environmental Reports for Fuel Fabrication Plants," a draft document dated January 1974, is the basic outline for evaluating the submittal. The EPM checks the radiation dose calculations for consistency with the accepted Regulatory Guide models and parameters referred to in the paragraph above. This review also serves to screen the submittal for controversial issues that might indicate a formal Environmental Impact Statement would be required. The radiation dose to the nearest resident from routine releases is checked to determine if the facility operation is in compliance with 1 imits in 40 CFR 190. If the doses from routine releases are less than the 40 CFR 190 limits and no impacts are evident that might be viewed as unacceptable, the decision will normally be made by the EPM to proceed with an Environmental Impact Appraisal (EIA) under the assumption that the eventual 
finding will be "no significant environmental impact." If the submittal is found to be essentially complete, a contractor is engaged to conduct the detailed review and environmental impact assessment.

The contractor then conducts a review of the submittal and may generate a list of questions and additional information requirements. This list is discussed with the EPM and transmitted informally to the licensee. The contractor reviewer, the EPM and (usualiy) an inspector from the appropriate Regional office then visit the licensee's facility to discuss the questions and obtain required supporting information. The Regional office and the contractor also contact State and other agencies having authority over various aspects of the licensee's operation to study the applicant's record of compliance.

During the visit, the questions are discussed and additional information is obtained to support the review. Approximately 1 month after the site visit, the contractor provides the EPM with a formal list of questions and comments which require answers or clarification. The list is transmitted by the EPM to the licensee with a request for response within a certain period of time (usually about 1 to 2 months). The licensee is requested to respond to the EPM. This may be done in several parts spread over a period of weeks or months as the information is generated.

On the basis of the licensee's original submittal, answers to the questions, information gathered during the site visit, and contacts with other regulatory entities (State Health Department, EPA, etc.), the contractor, guided by the EPM, completes an evaluation of the impact that the proposed licensing action will have on the environment. The contractor documents the evaluation in a draft Environmental Impact Appraisal which is provided to the EPM for internal review by the NRC. The EPM also requests comments on the draft EIA from other State and Federal agencies that have authority over (or specific interest in) various aspects of the licensee's operation.

When the internal and external comments on the draft EIA have been received and resolved to the satisfaction of the EPM, he authorizes the contractor to prepare the final EIA. This final EIA goes through another internal/external review cycle. After any coments on the final document have 
been resolved, the EIA is issued and a negative declaration (i.e., no significant environmental impact) is published in the Federal Register. The EPM then prepares a surmary of any environmental license conditions which he feels should be imposed and provides them to the Licensing Project Manager (LPM) for inclusion in the renewed license. 



\section{INTERVIEWEE COMMENTS ON THE LICENSING PROCESS}

The discussion below sumarizes the comments by NMSS staff, IE Headquarters and Regions, and the licensees. The discussion reflects both general comment categories and specific comments by individuals. Table 2 gives a breakdown of the comments by category and the number by times each category was addressed.

\section{COMMENTS BY NMSS MANAGEMENT AND STAFF ON THE LICENSING PROCESS}

- The Official Regulatory Base

Personne? are aware that requirements must be based on CFR or exist as license conditions. Requirements are of ten not distinguished from acceptance criteria.

- The Unofficial Regulatory Base

This subject is viewed with concern by the NRC's legal staff. Currently the Executive Director for Operations is advising the staff to comply with recommendations of the Executive Legal Director to avoid use of language suggesting that guidance or criteria contained in staff documents or letters to licensees are "requirements."

- Potential Changes in Regulatory Base

The staff encourages development of industry standards and will utilize those not referred to in Regulatory Guides when proposed by applicants and found acceptable to the licensing staff.

NMSS management cautions that rule making to clarify requirements should be approached with great care because it opens the door to public criticism. Compilation of criteria and guidance into Regulatory Guides is, however, an acceptable process.

- License Renewal Process

NMSS management and staff would like to receive more complete license applications so that questions are not necessary. 
TABLE 2. Surmnary of Comments on Licensing Process

Number of times each category was cited

\begin{tabular}{|c|c|c|c|c|c|c|c|c|c|c|}
\hline Comments by & $\begin{array}{l}\text { Official } \\
\text { Reg. } \\
\text { Base } \\
\end{array}$ & $\begin{array}{l}\text { Unofficial } \\
\text { Changes in } \\
\text { Reg. } 8 \text { ase } \\
\end{array}$ & $\begin{array}{l}\text { Potential } \\
\text { Changes in } \\
\text { Reg. Base } \\
\end{array}$ & $\begin{array}{l}\text { License } \\
\text { Renewal } \\
\text { Process }\end{array}$ & $\begin{array}{l}\text { License } \\
\text { Conditions }\end{array}$ & $\begin{array}{l}\text { License } \\
\text { Amendments } \\
\end{array}$ & $\begin{array}{l}\text { Inspection/ } \\
\text { Citation } \\
\text { Process } \\
\end{array}$ & $\begin{array}{c}\text { Probiems of } \\
\text { Existing } \\
\text { Process } \\
\end{array}$ & $\begin{array}{c}\text { NRC Staff } \\
\text { Capabilities } \\
\text { Interaction } \\
\end{array}$ & $\begin{array}{c}\text { Other } \\
\text { Comments } \\
\end{array}$ \\
\hline \multicolumn{11}{|l|}{ NRC } \\
\hline NMSS & 5 & 1 & 1 & 1 & & & & 1 & 4 & \\
\hline IE & 9 & 1 & 11 & 10 & 10 & 3 & 7 & $g$ & 22 & 2 \\
\hline L icensees & 24 & 9 & 17 & 16 & 15 & 4 & 3 & 28 & 15 & 4 \\
\hline Total & 38 & 11 & 29 & 27 & 25 & 7 & 10 & 38 & 41 & 6 \\
\hline
\end{tabular}

N 
- NMSS Staff Capabilities and Interactions

Headquarters staff is divided as to whether strengthening the role played by NMSS in licensing would be an improvement in the licensing process. A better explanation of the interface between the Licensing Project Manager and the 1 icensee is seen as needed.

\section{COMMENTS BY IE HEADQUARTERS AND REGIONAL OFFICES}

IE personnel commented on the regulatory base, existing licensing procedures, and interactions with NMSS.

Comments Regarding the Regulatory Base

- The Official Regulatory Base

Evolution of the regulatory base and posture for fuel cycle facilities has not kept pace with the development of technology and awareness of safety significance. Some of the deficiencies in regulations are producing problems for the NRC in contested hearings. It is feasible to extend the renewal period of some licenses without any effect on health and safety, but NRC does not do this partly because of objection by intervenors.

- The Unofficial Regulatory Base

NMSS is requiring licensees to make measurements not specified in the license in the case of particle size analys is of particulates emitted from air discharge stacks. The use of these data is not spelled out.

- Potential Changes in the Regulatory Base

10 CFR Parts 20 and 70 need upgrading. Specifically needed are the basic requirements for Health and Safety and Quality Assurance organizations, surface contamination limits, internal dose Timits, and reporting requirements for such matters as personnel exposures, unplanned releases, and changes in plant operations. Regional offices were evenly divided regarding the value of requiring license applications to conform to the proposed Standard Content and Format Guide as well as use of Standard Review Plan (SRP) for license review 
and the establishment of non-negotiable license conditions by NRC prior to license renewals. One view was to require a standard set of license conditions for all facilities, with supplemental SRPs to provide for differences between plants. Generally IE personnel felt that "de minimis" levels for surface contamination are needed. Technical specifications similar to requirements for power plants under 10 CFR 50, would be appropriate if devoted to health physics issues.

- License Renewal Process

There should be a time limit on the "timely renewal" of licenses. When questioned about the values of the renewal process, staff members at one Regional office said they preferred periodic license renewal to a long-term license with unlimited amendments. Two Regional offices felt that the license period could be lengthened or be flexible, depending on the particular circumstances.

Regional Offices generally want more involvement in the renewal process. Requests for IE review of proposed licenses for inspectability should allow sufficient time for review. Also, correspondence regarding questions and answers about license renewals should always be routed to the Regional offices.

- License Conditions

In some cases the number of conditions imposed on a licensee is excessive; this may be due to a poor quality renewal application submitted by the ricensee. Some staff members at more than one Regional office expressed concern that voluntary actions by the licensees are imposed as license conditions upon renewal. The license flexibility is unnecessarily reduced and costs of compliance increase.

- License Amendments

One Regional office expressed concern about the practice of NRC "soliciting the licensee to voluntarily commit to Ticense changes." Amendments should not be add-ons to the license. Instead, the pages of the original license should be modified to keep the total number 
of pages involved to a minimum. One Regional Office did not receive copies of amendments until after they were in place and consequently did not review them until planning their agenda for the annual

inspection of the facility concerned.

Problems of Existing Licensing Process

According to one Regional office, more specificity is needed in license conditions. They also see a need for stricter reporting requirements and a clear statement of the bounds within which operations are to be conducted. Also, requirements not traceable to CFR or license conditions should not be instituted.

Some regional staff members feel that NMSS review of Ticense renewa? applications would be more timely with more staffing.

NRC Staff Capabilities and Interactions

- Staff Capabilities

Time and manpower availability pose more problems for IE than technical problems of the licensees. Some IE staff expressed opinions that lack of health physics personnel at NMSS is causing delays in reviewing license renewals, and that all of the Licensing Project Managers at NMSS specialize in criticality safety, so other aspects of the health and safety licensing process may not be getting appropriate attention.

- Rejations between IE and NMSS

Relations are good but the regional IE offices want more involvement in license renewal. The extent of interaction of Licensing Project Managers with regions varies considerably with the individual LPM. Some regions would like to be involved prior to first transmittal of suggested license conditions to licensee. Furthermore, better communications between IE and NMSS would be helpful. One regional office mentioned that if the LPM periodically accompanied the IE inspector on his visit to the licensee's facility, the license renewal process might be unnecessary. Instead, just individual pages of the license would be updated. 
- Relations Between IE and Licensees

Relations between Regional offices and the licensees appear to be good. Licensee facilities are well run with few problems, and licensees generally are cooperative.

- Relations Between NRC and Other Agencies

Regional offices feel that they have good relations with concerned state agencies. One region has almost daily contact with EPA and State agencies regarding environmental monitoring of non-radioactive releases. One State requested that NRC inspect a facility located in a different State for conformance of its nuclear waste packaging procedures to the QA requirements of the State the waste was being shipped to; however, IE felt that action would be undue interference. As a rule, State or other agencies have regulatory responsibility for licensee activities that are outside the purview of the NRC. IE has memos of understanding with OSHA and MSHA defining responsibilities for standard process safety in fuel facilities (OSHA) and uranium mills (MSHA). IE inspects for conformance to local codes and insurance requirements regarding fire safety.

other Comments

Licensees generally have environmental monitoring programs far in excess of the requirements, because the programs were set up to be adequate for a much higher level of fuel cycle business activity than currently exists.

\section{COMMENTS BY LICENSEES}

The following text reports the comments of licensees who, in many cases, were very candid in their responses to questions and in offering additional views. The majority of the comments by licensees were directed to the licensing process rather than specifically to health and safety or to environmental concerns. A few of the corments did analyze the licensing process with specific health and safety or environmental regulatory bases as examples. 
Health and Safety Related Issues

In response to questioning about needed guidance and regulations, several licensees commented on the need for NRC to establish a de minimis limit for disposal of low enriched uranium (LEU)-contaminated waste. The presence of some level of enrichment should not transform this waste into special status. Environmentally Related Issues

It is believed unreasonable that the NEPA process must be completed (which takes at least 12-14 months) before plant construction can begin. As noted elsewhere in the comments, new applicants would derive more benefit from additional Regulatory Guides than would the established Ticensees. Comments on the Regulatory Base

With reference to the regulatory base, the following responses were given by 1 icensees:

- The Formal (Official) Regulatory Base

The comments varied from an acceptance of a Standard Content and Format Regulatory Guide with associated Standard Review Plan to "there are too many rules for adequate responsiveness." In place of additional regulations, Regulatory Guides, and review plans, what is needed is better personal communications and an improved review process.

One response to a regulatory guide for licensing/licensing renewal was based on a desire not to see the present LPMs restricted by regulatory guides and standard review plans in the licensing process. These restrictions may remove the right to negotiate. It was observed also that additional Regulatory Guides would be worth more to new LPMs, giving them a basis for negotiation plus better continuity from renewal to renewal. In contrast, more structure to the process is not needed because there are so few facilities existing or planned. In fact, there has been a decrease in the number of fue 1 fabrication facilities since 1976 and no new UF 6 facilities are likely for many years. 
While the reactions to additional regulatory guidance for license submittals or renewals was generaliy negative, several comments indicated willingness to cooperate; in fact, some indicated a wish to be included in their development.

- Unofficial Bases (Acceptance Criteria)

Acceptance criteria per se are not known by the licensee. Upon reflection some licensees believed individual LPMs use them, and related them to the LPMs background, competence and experience as an LPM. Licensees want to know what the acceptance criteria are so they can meet them on the initial submittal. In addition, one licensee not only wanted better guidance on acceptance criteria for given issues, but also what will be a good enough submission. Furthermore, the LPM often solicits voluntary compliance from the licensee. Since these discussions are often conducted by telephone, written correspondence may not contain an adequate record of discussion leading to oral agreements between the staff and the licensee. Consequently, the final renewed 3 icense or the amendment may be determined by how good the licensee personnel are as negotiators. Also, most discussions between the licesees and LPM seem to center on the licensee's deliberate omissions rather than errors of comission.

Any Regulatory Guide or Standard Review Plan should state requirements on a broad basis and should not limit licensees' flexibility by specifying the fine detail of implementation. Reservations were expressed about Regulatory Guides that attempt to delineate content, but another comment indicated areas that can be made more quantitative such as site evaluation, natural phenomena requirements, acceptable building codes, and quality assurance. Another respondent contended that the inclusion of standard license conditions or even technical specifications (such as in 10 CFR 50) may be acceptable but as much as possible should remain negotiable.

More than one respondent indicated the need to be able to negotiate criteria, plus having an input to changes or new regulations. Inputs by licensees to regulatory changes are not always incorporated. 
A primary goal of new regulatory guidance should be to eliminate the redundancy now existing in license submittals. Also, some regulatory guides are seen as violations of the law inasmuch as they are supposed to be only guides but are, in fact, laws imposed by administrative edict.

A broader license is a desirable goal. The licensees would like to operate under a license that specifies an envelope of acceptable operations and conditions rather than under a set of detailed requirements. If the regulations give broad ranges, then each licensee can decide how best to meet them. This flexibility would allow each licensee to meet the regulations in the most desirable, cost effective manner. This may lead to a variety of methods since opinions vary depending upon each licensee's capability.

There is no need for the NRC to review each detail and equipment change if the overall safety compliance is not degraded. Conversely, having technical specifications (like 10 CFR 50) could lead to ratcheting of requirements.

The method of regulation promulgation is viewed as unfair to the industry because it does not take into account industry concerns. Comment deadiines are often set without considering the publication time and mailing time for the Federal Register. Consequently if items are not caught immediately and scanned to decide if a comment is required, the deadline can be easily missed. Furthermore, because the industry comments seldom appear to influence the final regulations, it is very difficult for a licensee to justify expending the effort to provide constructive comments in the short time allowed. Some examples of rules which were thought poorly-conceived or improper ly imposed were given: 1) The requirement to upgrade a rule for certain barrel handiing operations, requiring them to be done in a separate area by personne 1 who do not have access to the fuel area, is impossible for one $U_{6}$ licensee to retrofit. 2) A new rule, effective in February 1981, that required modification of the 
Security Plan for physical access to highly enriched uranium, was unclear as published, and no deadline for a request for license amendment was specified. 3) The NRC started using the categories of civil penalties after Congress passed enabling legislation, and the NRC Commissioners instructed the staff to implement the system even before the proposed rule was published.

License conditions may be imposed by the NRC at any time through a letter, such as the decomissioning plan, for example. Such Ticense conditions do not seem to be organized according to any central philosophy of the NRC.

Although some licensees identified areas where license conditions could be more quantitative, a 10 CFR 50 approach is not wanted, while flexibility and negotiable conditions are. One Ticensee objected to "best" (most expensive) techniques being made universal. Several licensees rejected the common denominator concept for requirements for all licensees. Licensees should have the prerogative of selecting compliance methods that are technically sound, whether or not they are universal.

Comments by Licensees on NRC Staff Capabilities

The comments on the relationships with NRC staff varied. All license managers were seen as well qualified and functioning well as LPMS. Occasionally, an LPM was seen as hesitant to make decisions in a timely manner. Another licensee viewed some of the NRC staff as having very good backgrounds in fue? fabrication but lacking the appropriate background in the area they are regulating. As a result, the costs and time schedules are not always realistic. It was perceived by one licensee that he has been functioning more or less continuously as a trainer of licensing managers in his area. Another has had little problem with inexperienced NMSS/IE personnel.

The turnover in the top management of regulatory agencies creates problems for and pressures on the licensees, as boundary conditions inevitably change. For example a former member of NMSS management required LPMs to keep tight deadlines, but the current manager and staff are more flexible. New LPMs need 
4-5 years' industrial experience; should visit the plants; and should be aware of lead times, equipment delivery delays, and capital investment requirements. Impact of Interactions of NRC with Other Agencies

One licensee noted that he deals with eight different licensing bodies, mostly local. He also observed that the NRC is a pass-along point for any governmental agency requirement without any filtering. The resulting inconsistency increases the licensee's load. Another cited an NRC license condition originating with EPA, who, in turn, were responding to a state request. It involved a liquid effluent monitoring program which was dropped after one year. The cost was $\$ 4 K$ and the effort was ineffective because the potential release (tritium) was in the gaseous state. NRC should assert its expertise rather than just pass along requirements without evaluation.

One licensee is concerned about possible overlap of jurisdiction and interpretation of non-compliance reports. An example was cited of EPA monitoring chemical discharges and then notifying NMSS.

Another licensee believed that IE should be involved with NMSS from the beginning in the licensing process.

Several licensees commented on the lack of flexibility in routine operations as a result of license conditions. It was proposed to alleviate this problem by identifying non-negotiable license conditions and placing them "up front." The licensee should be free to operate his facility within the license requirements and retain the prerogative to change operating procedures or calculations without violating his license. That is, such items as methods or implementation of procedures should not be a part of the license conditions. Regular procedures on the shop floor do not need to be imposed as part of the license. The qualifications of the licensee staff, their experience, and facility compliance history should be the major basis for license renewal.

License conditions often duplicate what is in the license. This duplication can be eliminated by self-imposed license conditions. However, most Tast minute license conditions are imposed by mutual consent between LPM and licensee. At that point in the licensing process, it is easier and quicker than submitting change pages to the license application. 


\section{License Renewal Process}

- Renewal Interval

A11 licensees commented on this subject with comments ranging from a general acceptance of the 5-year length for a license renewal to a desire for an indefinite license. The supporters of a 5-year renewal reasoned that while a 5-year renewal interval is difficult, a 10-year renewal interval would be worse in terms of an effort to accomplish renewal.

Granting an indefinite license was proposed, subject to a periodic rework of the documentation to make it readable and usable.

- Renewal Process

Basic concerns about the renewal process were expressed in that the timely renewal phase, while very useful, leaves the licensee vulnerable, worries management and their legal staff, and is perceived as a risk. In addition, an objection was raised over the arbitrary nature of the process which forces the licensee to start over for each renewal with expectations of a new, more restrictive license. The process does not recognize or consider a licensee's performance, facitities, or personnel.

Part of the concerns about the renewal process relate to the question-and-answer process and lack of formal guidance. One licensee suggested that the renewal process would be no longer or more involved if a short letter plus form sheets were forwarded, citing their record and proposing renewal, and then waiting to proceed through the inevitable questions and answers. This is an example of the licensee's frustrations with the Q\&A process.

- Guidance in the Renewal Process

In general, licensees did not believe that additional formal guidance would be of benefit to them in the renewal process. The majority felt intuitively that they could successfully initiate a request for renewal based on the format of their existing license. It was noted 
that little guidance exists for the newcomer except to use licenses for existing facilities as found in the Public Document Room. Eliminating the redundancy that develops in the format of existing licenses is one benefit that would result from guidance. For more than one present licensee, licenses of competitors have provided substantial guidance.

One licensee proposed that both NMSS and IE be involved in the licensing process but not necessarily include the licensee in their preliminary internal interfacing.

- Questions and Answers in the Renewal Process

Meetings between licensees and NMSS were proposed to resolve all questions, thereby eliminating much of the $Q$ and $A$ process. The $Q$ and $A$ process is a costly one for licensees. Due to the sometimes long intervals between response to questions and NMSS reaction to the answers, the licensee must regroup his specialists from the ir current tasks. Long delays diminish the effectiveness of the questions and answers in the licensing process.

- Inspection/Citation Process

IE inspectors are generally thorough and consistent. Some inspectors discuss all license conditions and amendments in detail with license staff prior to inspections. Agreement is reached on what they mean, how they are integrated, and how they will be inspected. This procedure is very useful because the inspectors are not necessarily involved in the negotiations and agreements between NMSS and the Ticensee.

Licensees noted that IE failed to acknowledge when performance exceeded requirements; inspection was strictly to license conditions. However, if IE seemed dissatisfied with the licensee's implementation, the unresolved items showed up later as added license conditions. The licensees making this point thought there should be more give and take based on the total performance picture. 
Genera] Critique of Current NRC Licensing Process

Licensees support the concept of licensing by objectives rather than methods imposition; i.e., the license should be mainly oriented to performance and not procedures.

Licensees were particularly concerned that conditions are imposed on all because of a problem with only one or a few. The various licensees (as seen by each one) represent a broad range of responsibility, ability, integrity, and responsiveness to actual needs. An example of particular concern is the generic order on Radiological Contingency Plans. Instead of a blanket order, the docket files should have been examined to see what was needed on a case by case basis.

Communication was a pervading theme of many of the comments. The licensees want better personal cormunications and an improved review process. One licensee would like to see periodic meetings (such as their quarterly meetings with NRC Safeguards staff) at which a11 commercial fuel fabricators could meet with NMSS and discuss upcoming changes in safety requirements and regulations.

Delays in the process, in part attributed to the system, are counterproductive. According to one licensee, an application takes 2 weeks to get to the appropriate desk at NRC. When the licensee spends 3 months preparing a response to NRC, and NRC requires 6 months to reply (round two), the renewal process loses continuity.

Same legal concerns surfaced. One licensee stated he has learned the hard way that following NRC regulations does not relieve him of liability, and also that the LPM does not have a clear picture of his own legal base.

One licensee summed the feelings of several others in emphasizing that because the licensing and regulatory system has never been fully planned, there is no consistent structure to it.

One licensee believed the license renewal process is not a tidy system but it does work. The requirements are not all written in the Code of Federal Regulations. It is necessary to understand NRC's intent with respect to formal regulations rather than just the way the regulations are written. The Code of 
Federal Regulations is good as a start, but in order to retain the license the licensee must also meet many other requirements given in referenced Regulatory Guides, ANSI Standards, NUREG reports, and NRC policy statements and letters. Regulators have broad authority. Regulatory Guides and NRC policies have informally required in vivo determination of deposited uranium, operator training, and decomissioning plans without changes in 10 CFR 70. However, these requirements can be negotiated to a reasonable level of effort and cost. In the past the licensee has taken a conservative position when requirements are not clear, but he can no longer afford to be overly conservative because of the profit picture.

\section{Other Comments}

The value of public rulemaking in the licensing process was discounted by one licensee because there would be strong pressure for uniformity. Instead, a systems review of the entire licensing process is needed to coordinate and balance all the licensing steps. In this manner an overall series of coordinated goals can be reached. An example of the current problem is that a licensee may be given only 90 days to implement an unacceptable license condition or to propose an acceptable alternative. This may not be physically possible, and no reasonable alternatives may exist.

Another licensee noted, however, that because the public is involved, licensing cannot be a simple process. Intervening by the public can cause delays inasmuch as NRC licensing personnel must then respond to intervenors' questions in addition to performing their assigned license renewal/amendment tasks. Also, time must be taken to respond to an intervenor's request that is passed through a Congressman, a very effective way for intervenors to disrupt the licensing process, according to this licensee.

Finally, although not a part of this task, comments were received on the license amendment process. Without exception the comments have been, "the NRC response on amendments has been very satisfactory and the paperwork generally flows smoothly." 



\section{PNL OBSERVATIONS}

This section details the observations made by PNL based on the results of the in-depth analyses and interviews. The following discussion is centered on the enforceability and adequacy of the regulatory base; changes in the licensing process; the question-and-answer exchange; and the role of the Inspection and Enforcement office.

\section{ENFORCEABILITY OF THE REGULATORY BASE}

The NRC. Executive Legal Director ${ }^{(a)}$ emphasizes that staff positions communicated to licensees are not binding requirements unless formally issued as regulations, set forth in orders, or decided by an appropriate Commission adjudicatory body. Other sources that are not legally binding include NUREG reports, Regulatory Guides, Standard Review Plans, Policy Statements, and ANSI Standards. However, as a practical matter the Regulatory Guides and sometimes additional sources are considered binding because departure from them can result in considerable delay in reviewing license applications. Consequently, there is a proliferation of "quasi requirements" with resultant confusion on the part of both NRC staff and licensees as to what binding requirements are in place at any given time. This situation is further complicated by inclusion of extensive reference citations in each licensee's submission of Technical Specifications (i.e., License Conditions) in support of their new or renewal license application.

Examples of quasi requirements are the Regulatory Guides that deal with criticality safety rather than radiological consequences of accidental nuclear criticality. These Regulatory Guides include:

1. The proposed revision 1 to Regulatory Guide 3.1, "Use of BorosilicateGlass Raschig Rings as a Neutron Absorber in Solutions of Fissile Material" states "The guidance contained in ANSI/ANS 8.5-1979 for the

(a) Memorandum to the Directors, NRR, NMSS, IE, and OSD from Howard K. Shapar, Executive Legal Director, dated Feb. 5, 1981. Subject: Avoidance of Mischaracterization of Effect of Certain Communications to Licensees, Transmitted to the NRC commissioners by EDO memorandum dated March 9, 1981. 
use of borosilicate-glass Raschig rings as a neutron absorber in solutions of fissile material provides a procedure generally acceptable to the NRC staff for the prevention of accidental conditions of criticality."

2. Regulatory Guide 3.45, "Nuclear Criticality Safety for Pipe Intersections Containing Aqueous Solutions of Enriched Uranyl Nitrate" refers to ANSI/ANS 8.9-1978, with the same title. The guide states, "The nuclear criticality safety practices and guidance for calculating safe pipe intersections for enriched uranyl nitrate solutions contained in ANSI/ANS 8.9-1978 provide procedures genera11y acceptable to the NRC staff for the prevention of criticality accidents in the storage and processing of aqueous solutions of enriched uranyl nitrate in pipe intersections."

3. Regulatory Guide 3.47, "Nuclear Criticality Control and Safety of Homogeneous Plutonium-Uranium Fuel Mixtures Outside Reactors," refers to ANSI/ANS 8.12-1978 which has the same title. The guide states, "The maximum subcritical limits for operations involving homogeneous mixtures of plutonium and uranium outside reactors contained in ANSI/ ANS 8.12-1978 are acceptable to the NRC staff when all conditions of ANSI/ANS 8.12-1978 are satisfied." Hence, ANSI/ANS 8.5-1979, ANSI/ ANS 8.9-1978, and ANSI/ANS 8.12-1978 appear to have become additional quasi-requirements.

4\&5. Two guides dealing with criticality safety refer to ANSI standards by stating that the standards are not a substitute for detailed nuclear criticality safety analyses for specific operations or for specific storage arrangements for fissile materials. The conclusion must follow that some ANSI standards are useful primarily for presenting methodologies which are acceptable for use but are insufficient by themselves in proving safe operation. The two guides are: Regulatory Guide 3.4, "Nuclear Criticality Safety in Operations with Fissionable Materials Outside Reactors," which refers to ANSI N16.1-1975, (similar title) and Regulatory Guide 3.43, "Nuclear Criticality Safety in the Storage of Fissile Materials," which refers to ANSI N16.5-1975, (similar title). 
6. The final case involves Regulatory Guide 3.41, "Validation of Calculational Methods for Nuclear Criticality Safety," that refers to ANSI N16.9-1975 which has the same title. The guide states, "The guidelines for validation of calculational methods for nuclear criticality safety contained in ANSI N16.9-1975 provide a generally acceptable procedure for establishing the validity and area of applicability of calculational methods used in assessing nuclear criticality safety. However, it will not be sufficient merely to refer to this guide in describing the validation of a method, The details of the validation indicated in Section 4.6 of the standard should be provided to demonstrate the adequacy of the safety margins relative to the bias and criticality parameters and to demonstrate that the calculations embrace the range of variables to which the method will be applied."

The situation of binding requirements versus quasi-requirements is further confused by the practice of referring to other parts of the license application. An example can be cited in the criticality safety portion of the Rockwe11 International license. The NRC Materials License SNM-21, Docket 70-25, issued 9/15/77 states as condition 9 - "Authorized use: For use in accordance with statements, representations and conditions contained in Sections VII-B, VII-C, and VII-D of the licensee's application dated June 27, 1975 and supplements dated February 1, Apri1 13, June 16, and August 12, 1977." In Section VII-D Criticality Safeguards, pages VII-52 through VII-78, several documents are referenced. These documents include: ARH-600 Volume $1, K-1380$, K-1478, K-1619, LA-3366 Rev, ORNL-2367, SC-RR-65-98, TID-7016 Rev 1, TID-7019, TID-7028, TR-466, Y-CDC-13, and Y-1272. These documents are used to obtain generally acceptable methods, nuclear safety guidance or rules, acceptable safety criteria, and experimental or calculated data. None of the listed documents are specifically included in the binding regulations, but are all part of the regulatory base. Some are used so extensively that they have become quasi-requirements. Furthermore, some of the documents provide criteria, which, in many cases, are dependent on the methods used. 


\section{ADEQUACY OF THE REGULATORY BASE}

There is understandably a difference of opinion between NMSS and the licensees on the adequacy of the regulatory base, but there are also differences among the licensees on what is essential for the renewal licensing process. Some licensees would like the regulatory base very narrowly construed, while others prefer a more general atmosphere in which to negotiate renewal Ticenses. For its part NMSS would like to see submittals so complete that there would be no need for question and answer exchanges. However, to accomplish complete submittals, the licensees must know in advance precisely what is required and must be willing to impose appropriate conditions on themselves.

During the time interval examined by PNL the licensees did not appear to have advance knowledge of requirements for renewal submittals, and were unwilling to impose conditions on themselves without devoting a fair amount of time to negotiation. The economic self interest of the licensees dictates that they put significant pressure on NMSS, especially if the licensing requirements are not clearly identified beforehand. The strong impression was given to the study team from all parties that NMSS had no desire to specify in advance the ir non-negotiable positions. By implication, everything not spelled out in the regulations was thus negotiable. The other aspect of licensee perceptions that contributed to prolongation of the renewal process vis-a-vis the amendment process was the "timely renewal" provision. The licensees saw no urgency to get the renewal license in place, although this cause of delay had nothing to do with the adequacy of the regulatory base.

The obvious solution to the problems of adequacy and delay might be to hold a formal rulemaking to identify and make non-negotiable those requirements which have been the subject of the most time-consuming negotiation. Such an action will not be welcomed by licensees who feel they have more to gain through negotiation than by $c$ larification of the regulations. NMSS may not. wish for the visibility of a rulemaking because of the potential for criticism that any such action to convert de facto requirements to de jure requirements is an unwanted increase in regulation. 
Other, less direct methods to enhance the regulatory base were considered by the study team, together with the effect of such changes on the licensing process. These methods are described below:

1. Much material used in the licensing process is not controlled or coded and is scattered throughout many publications. It would be useful to all parties of the regulatory process if the various computer codes and reference documents which are not already in the form of Regulatory Guides could be collected and compiled into that form.

2. The Standard Format and Content Guide for Health and Safety Aspects of Uranium Fuel Fabrication Plants could be issued as modified by the comments in Appendix $C$ of this report. The document could be expanded to include UF ${ }_{6}$ conversion facilities. If the Guide is issued, the associated Standard Review Plan should be prepared. Separate guidance should be prepared for the Environmental Report. These documents should reference all Regulatory Guides or other reports that NMSS believes are necessary or useful in the preparation of 1 icense renewal submittals.

Licensees who believe that they need no additional guidance for the preparation of licensing submittals will still welcome the Guide because it can help them find specific information in submittals by other fuel suppliers in the Public Document Room. They will oppose the Guide if they feel it hampers their flexibility. Experienced Licensing Project Managers in NMSS will oppose it for the same reason. New LPMs will find the Format and Environmental Guides and SRPS indispensible. NMSS managenent must decide whether this form of enhanced regulatory base is useful to their operation.

3. A pre-licensing conference among NMSS, IE, and the licensee would be useful to establish what information is needed in the renewal submittal. NMSS could then formally issue the acceptable license conditions for a particular licensee. This selective licensing process will preserve the LPM's flexibility to establish the most appropriate license conditions while making visible the regulatory control that 
is being exercised. Published measures of performance such as the Systematic Assessment of Licensee Performance (SALP) will support the selective licensing process.

4. Criteria used by NMSS in evaluating license submittals should be clearly distinguished from requirements which the licensee must meet. Only the latter need to be the subject of a rulemaking if they are not already part of the regulations, an order or legal decision applicable to the licensee. The criteria could be published in a NUREG to give guidance, rather than requirements, to licensees. Letters dated early in 1981 by the NRC's Executive Legal Director and the Deputy General Counsel were given the study team by NMSS staff. The legal opinions pointed out that many improperly given requirements were generating confusion among NRC "practitioners" as well as licensees. This opinion was supported by the Executive Director for Operations. While NUREG documents were specifically referred to as containing unenforceable "quasi requirements," the study team feels that the opinion also applies to the situation where license conditions (orders) attempt to make compliance with Regulatory Guides and ANSI Standards mandatory.

If true requirements are cleanly separated from criteria and methods of analysis, any necessary rulemaking will be greatiy simplified. An important example would be the setting of de minimis levels of contamination for certain liquid and solid wastes. This suggestion was put forward by many of those interviewed. When rulemaking is seen as a means of liberalizing the Ticensing process, there can be little objection that so-called "new regulations" are being imposed. An extensive analysis of the criteria and guidance used by the L.PMS is presented in Appendix B.

\section{EFFECT OF CHANGES IN THE LICENSING PROCESS}

Suggestions were made to the study team that the renewal Ticensing process be greatly modified or eliminated altogether. The arguments were that the fue? fabrication and UF 6 conversion processes were sufficiently stable over the years that amendments and orders could easily keep the license up to date. 
However, the NRC's comitment to review older licenses under part 50 of CFR would make it difficult to drop part 70 reviews. The process of making UF 6 or $\mathrm{UO}_{2}$ may change little, but knowledge of hazards and their control can change greatly. The law itself changes as well as the understanding of how to apply it, especially in the field of environmental protection. License evolution by amendment tends to create an uneven result; there is little assurance that the licensee has considered the broadest impact of the change he is requesting. Merely substituting change pages to keep the license alive creates a nightmare of record-keeping, as the study team found in its review of the document files. Also, incremental changes, each deemed "inoffensive," can add up to a substantial change that would be unacceptable. This kind of licensing "creep" is especially likely where new LPMs come in unaware of the detailed licensing history.

For these reasons, the study team believes it is inadvisable to depend solely on the amendment/order process to keep licenses up to date. Amendments initiated by the licensee should be limited to major changes in the process or emergency measures that cannot wait until the next renewal.

There are changes that can be made to streamline the license, that should not require the machinery of a total review. Parts of the Safety Demonstration portion of the license must be kept up to date if it is to be effective. The organization chart, emergency contacts, and figures that become obsolete should be changed by letter as often as necessary.

Another area of licensing improvement that NMSS management should consider is the arbitrary time of 5 years between renewals. The renewal period should be flexible, based on the activity associated with the license, e.g., seriousness of deficiencies found in inspection, frequency of request for amendments, plant expansion, or change in throughput resulting from changes in the economy. Once the renewal period is chosen, a detailed schedule should be agreed to by a11 parties: IE, NMSS, and licensee. This schedule is necessary to eliminate the abuse of "timely renewal" by intentional delays via the question-and-answer process.

Because there are so few new facilities envisioned in the next several years, licensing renewal should be the central activity of the Uranium Fuel 
Licensing Branch of MMSS. All other activities, including amendment review, should be subordinated. Only then can reasonable renewal schedules be maintained.

\section{QUESTION-AND-ANSWER PROCESS IN LICENSING RENEWALS}

In the environmental area, the questions seem to arise largely from the lack of specific guidance to the licensee concerning the required content of the environmental submittal. Many of the informal questions raised by the reviewers are resolved during the site visit. Ideally, all questions would be resolved at that time, eliminating the need for the time-consuming exchange of lists and correspondence. This might be possible if all the questions were simply matters of clarifying or amplifying the information contained in the environmental submittal. However, requests for significant amounts of data, without which the submittal cannot be properly evaluated, of ten require weeks for the licensee to respond. Most of these questions could be eliminated by proper guidance to the licensee on the required content of the environmerital submittal.

The question-and-answer exchange is a source of frustration for all participants. NMSS staff generally felt that licensees were providing less information than was required or requested. Licensees expressed opinions that most questions arose from the LPM's desire to document his stewardship of licensing process rather than from a genuine need to elucidate further facts. Inadequate guidance on preparation of submittals was also cited as the reason for many questions. It has been difficult for the study team to analyze the process because much of the negotiation between the LPM and the licensee is not visible. No formal record of negotiation on the Q's and A's is kept. The application itself contains the result of much preliminary discussion.

Relation of Question-and-Answer Process to Safety Evaluation Report (SER)--The Westinghouse Case

The formal question-and-answer process is important mainly for its impact on the recommendations in the SER. The SER contains the justification for the Health and Safety license conditions imposed. For example, one recent SER (March 1978) which imposed a large number of license conditions (48) was for 
the Westinghouse Columbia Plant. The application for renewal was submitted on December 30, 1976. According to the revision record, it had been revised in its entirety. An earlier submittal in 1974 had received no action by NMSS.

A list of 87 questions and comments was compiled by the LPM and sent to Hestinghouse on May 27, 1977 (see Appendix D). In late July, after some discussion in the intervening period, Westinghouse agreed to respond in three parts: on $8 / 19$, on $9 / 30$, and on an indefinite date. They also offered to negotiate a conditioned renewal after $9 / 30 / 77$. By responding to some of the questions as the answers were developed, Westinghouse felt the review process would be expedited.

Responses to 61 items were submitted on $8 / 19$, together with the statement that 25 items remained to be resolved. On 0ctober 7, 10 additional responses were submitted, and on 12/30, 16 responses were received by NMSS. According to Westinghouse letter, dated $10 / 7$, question 70 was cancelled. Irrespective of the cancellation, a total of 87 revisions had been recorded. Evidently, the record was not yet complete, because three additional sets of responses were recorded prior to issuance of the SER on March 31, 1978: three items on $2 / 6 / 78$, four items on $3 / 3 / 78$, and five items on $3 / 28 / 78$. We assume all 99 items were a part of the record considered by the SER. A year after the SER was issued, the revision process began again and continued at least through mid-1980. It also appears that the actions taken to continually amend the 1 icense may overlap actions involving the renewal process only. The distinction between these two processes is that renewal opens up the whole license to review while amendment is 1 imited to narrow subject matter.

In our analysis of the questions and answers, we made the presumption of equivalence of importance of all items. Sorne are undoubtedly viewed as crucial by NMSS or Westinghouse and others not, but the contested items represented only about $16 \%$ of the total number (87) given in the May 27, 1977 letter of NMSS. In some cases, calculations or evaluations were submitted, but their acceptability was questioned (i.e., Jicense conditions were imposed). In 49\% of the cases, the items were represented by the acceptance of changed pages to the application. Unfortunately, the fate of many items (28\%) was not traceable because of subsequent changes to affected pages. This is a problem with the "living" license. 
Correlation of the questions and answers with resolution in the SER shows that at least 13 conditions ("Not withstanding...") were imposed despite the acceptance of changed pages to the license application. These represent the short fall of a licensing policy which seeks to induce the Ticensee to impose all necessary conditions on himself. A short fall of $15 \%(13 / 87)$ is not insignificant.

According to Westinghouse, 22 items were purely a question of timing: it was quicker to have a mutually agreeable license condition or annex imposed than to add more change pages. Five other items, they felt, were put in because other licensees had similar provisions. Two other items were already in the license, but were singled out as license conditions for visibility. One other item was put in at the request of an inspector and the last license condition was only necessary to incorporate a separately submitted decomissioning plan. A1l other license conditions were standard items.

According to the SER, the 42 non-standard license conditions imposed can be categorized into four groups. Nearly half (three groups) represent specific authorization, clarification or inspectability, but over half (22) specify particular safety items or procedures which the licensee was unwilling to incorporate into his application. In terms of the 99 items accepted as revisions to the application during the review period, 22 is a substantial number of items to go unresolved until the end of the review.

Attempts by NMSS management to accelerate the review by writing a strongly worded letter to Westinghouse and setting tight internal schedules were not effective. Westinghouse felt that nearly all 87 items were in some degree negotiable. If NMSS felt otherwise, there is no record of it.

Question-and-Answer Process Relative to SER--The Rockwell International Case

A parallel study was made of the licensing renewal for Atomics International (AI) headquarters and Nuclear Field Laboratory sites, Docket 20-25, dated June 27, 1975. Additional submittals occurred in August and November. Today AI is Rockwell International, Energy Systems Group, Canoga Park, California.

After docketing and other preliminary steps, the NRC started initial reviews in mid-January 1976 . The initial criticality safety review was 
completed $3 / 5 / 76$ by the LPM in the Fuel Processing \& Fabrication Branch. The initial radiation and nuclear safety review was completed $6 / 7 / 76$. The initial process safety review was completed $10 / 21 / 76$. Additional criticality safety review questions were also attached. The initial fire safety review was completed $11 / 29 / 76$ by the Fuel Cycle Environmental Projects Branch. The above four reviews all resulted in preliminary lists of comments and questions. $A$ quality assurance review was requested from NMSS, but the reply was not available to PNL. The LPM has indicated that all quality assurance questions were handled informally in discussions with Atomics International and, therefore, did not result in formal questions and comments.

An initial familiarization visit to the AI facility was made in November 1975. While the reviews were in progress, the NRC Headquarters staff discussed the application and compliance history with Region $V$ personnel. During 0ctober 1976, the initial comments and questions were transmitted informally to AI, and discussions were held by phone.

During the period November 1-5, 1976, the LPM and another staff member visited the AI plant and met with AI personnel. In addition to touring specific facilities, discussions covered radiation safety, fire protection, nuclear criticality safety, process safety and quality assurance comments and questions on the AI license renewal application. Radiological safety data accumulated over the previous two years of operation was also discussed. There was general agreement that the proposed responses by AI to most of the initial NRC comments and questions were acceptable. However, in the NRC's opinion, AI was insufficiently prepared to respond to several comments associated with nuclear criticality so that the NRC staff could determine the acceptability of the related responses.

On November 8-9, 1976, other NMSS staff visited and toured the AI facility. They met with AI and ORNL personnel to discuss matters related to the environmental review for the AI license renewa

A final visit to AI took place March 15-18, 1977, when the LPM accompanied IE staff on a routine inspection. The LPM also continued to discuss comments on the nuclear criticality safety sections of the application with IE staff. 
On March 29-30, 1977, another meeting was held with AI personnel and Region $V$ IE staff to discuss proposed conditions related to radiation safety. Proposed additional license conditions principally associated with nuclear criticality safety plus organization and administrative procedures were discussed 4/8/77 over the telephone by the LPM and Region V IE personnel, and were submitted in writing $4 / 21 / 77$ for IE review. In a 5/23/77 memo from Region $V$ IE to NMSS, it was stated that IE comments and suggestions had been satisfactorily incorporated, and IE concurred in the renewal of the AI license.

The NRC comments and questions were formalized with a 12/6/76 cover letter plus four attachments requesting additional information. This was the only formal transmittal of comments and questions made to AI during the license renewal process.

The AI Response to the comments and questions occurred in five transmittals. On 2/1/77, 35 pages of direct responses to NRC Comments and Questions were sent, plus 239 changed pages for insertion into AI-75-46; plus an enclosure concerning Emergency $\mathrm{P} 1$ ans from AI-75-21: "Environmental Impact Assessment of Operation at Atomics International Under Special Nuclear Materials License No. SNM-21"; and six additional resumes. On 4/13/77 another set of 126 changed pages was sent for insertion into AI-75-46: "Technical Information in Support of the Atomics International Application for Broad Nuclear Material License." On 5/24/77, a certificate of nuclear energy liability insurance was mailed. On 6/16/77, a revision of requested possession 1 imits for special nuclear material license SNM-21 was transmitted. Finally, on $8 / 12 / 77$ the first page of the application was modified to be in agreement with revised possession limits.

The 12/6/76 formal list of 70 NRC comments and questions in four categories was compiled by the Fuel Processing and Fabrication Branch of NMSS. AI responded to all 70 comments and questions 2/1/77. Of the AI responses, 55 only referred to change pages for AI-75-46 being submitted concurrently. Another 6 were answered by narrative responses plus changed pages for AI-75-46. The remaining 9 were answered by narrative responses only and did not result in any changed pages dated $1 / 24 / 77$. Additional detail is given in Table 3 . 
An analysis of the NRC comments and questions to AI dated $12 / 6 / 76$ suggests that an artificial gathering of all questions into one submission is not only inefficient, but is unrealistic in terms of what actually happens. The four initial reviews of criticality safety, radiation safety, process safety, and fire safety were completed by $3 / 5 / 76,6 / 7 / 76,10 / 21 / 76$, and $11 / 29 / 76$, respectively. Discussions by telephone, visits to the AI facilities, and informal transmissions of comments and questions occurred from October 1976 through March 1977. This demonstrates a considerable interactive exchange between AI and the NRC.

Of the 164 pages for AI-75-46 revised $1 / 24 / 77$ in direct response to NRC questions, $48 \%$ were re-revised $3 / 18 / 77$. In all, a total of 239 revised pages for AI-75-46 were dated $1 / 24 / 77$ because some sheets corrected only typos or management titles, enhanced overall quality and legibility of figures, or included editorial changes. Added enclosures mailed 2/1/77 were the Emergency Plans from AI-76-21 and six resumes.

The second round of changes for AI-75-46 included 126 pages dated 3/18/77. It is apparent from examining these technical modifications that there was a second round of NRC comments and questions which led to substantive changes in both the descriptive and the technical specifications section.

Comments on the Westinghouse and Rockwell Renewals

PNL does not question the need for modifications to the 1icensee's application after it is reviewed, but the protracted nature of these reviews is unreasonable. NRC transmission of questions after each distinct stage (or portion) of the review process would be appropriate, and would give the licensee a subset of the comments and questions to work on while other parts of the NRC review proceed. It would provide quicker feedback to both the licensee and NRC so that the work is not completely forgotten between exchanges. The workload could be more spread out and major disruptions to personnel schedules would be avoided. The whole process of iteration to acceptable application documents should be accelerated by this method, and should be acceptable provided that traceability of documents and letters is maintained. 
Many delays could be avoided if NMSS formally presented the non-negotiable items early in the review process, well before the applicant makes his submittal. Then NMSS is on record for the 1 anguage that should be incorporated into the submittal, rather than depending on oral agreements. The wording of nonnegot $i$ able items can be set at a pre-submittal conference among NMSS, IE, and the licensee.

\section{ROLE OF THE IE OFFICE IN THE LICENSE RENEWAL PROCESS}

The regional IE inspectors interviewed said they had little input to the license renewal process, but would prefer to have a greater role. Despite lack of involvement, most inspectors have a good relationship with their counterpart LPMs. In addition, the inspectors are highly regarded by the licensees. NMSS could take better advantage of these relationships and involve the inspectors in all licensing $p l$ anning and scheduling activities relating to their facilities. In particular, IE should participate in a pre-licensing conference with NMSS and the licensee to develop the required license conditions and determine their inspectability. During the application review, the LPMs should consult the inspectors regarding their areas of expertise. Finally, the inspectors should have ample time to review the draft integrated SER and EIA. These documents are identified in Figure 1 as steps S16 and E15. 
TABLE 3. Analys is of A.I. Answers of $2 / 1 / 77$ to NRC Coments and Questions of $12 / 6 / 76$

- NRC Question Title AI -75-45 Pages Changed

I. FACILITIES ANO OPERATIONS AT HEADQUARTERS Enclosure 1 - Nuclear Critical ity Safety Revien

NRC Comment or Question

Cited Basis

$3 / 18 / 77,3 / 18 / 77$

Revise figure to show location of work stations,

1. Page $V-8$

Page $V-8,-9$ (Figure $V-1$ )

-

2. Page $V-13$

Page $V-13$

3. Page $\vee-14$

Page $C-10 a$

$3 / 18 / 77$

4. Page $V-16$

$P$ ages $V-16,-16 a$

$3 / 18 / 77,3 / 18 / 77$

5. Page $V-18$

Page V-18, -18a

$3 / 18 / 77$, -

6. Page $v-19$

Pages $V-19,-19 a$

$3 / 18 / 77,3 / 18 / 77$

7. Page $v-20$

$P$ ages $v-20,-20 a$

$3 / 18 / 77,3 / 18 / 77$

8. Page $\vee-26$

Pages $V-26,-32$

$-, 3 / 18 / 77$

9. Pages $V-30, V I I-57$

Pages V-30, VII -57

$-,-$

10. Page $v-32$

Pages $y-32,-33,-33 a$

$3 / 18 / 77,-3 / 18 / 77$

11. Page $V-33$

Pages $v-33,-33 a$

$-, 3 / 18 / 77$

II. FACILITIES AND OPERATIONS AT THE NDFL

1. Page VI-25 Pages VI-25, -25a

$3 / 18 / 77,3 / 18 / 77$ equipment, stor age

Provide consistency with VII-D-2b, Item 3

Include uranium metal pickling as a type operation

State basis for moderation control in glove boxes affected by sprinklers.

State basis for maximum safe volume based on moderation of $B$ compacts

Discuss criticality safety in outgassing, furnace and hot rolling operations

Discuss annealing tray cart and annealing furnace and bases for criticality safety

Discuss criticality safety of mixed arrays of storage racks and safe carts

Delete flux-weighted solid angle method from document

Clarify method of analysis; delete descriptive text above figure

Reconcile migration area; specify administrative controls; verify conservatism

ANL -5800 , ARH -600

Specify equivalency of $241 \mathrm{pu}_{\mathrm{u}}$ with $239 \mathrm{p}_{\mathrm{u}}$; Reconcile different $\mathrm{Pu}$ mass 1 imits 


\section{TABLE 3. (contd)}

* NRC Question Title AI -75-46 Pages Changed iI. RADIATION AND NUCLEAR SAFETY (TECHNICAL SPECIF ICATIONS)

1. Pages VII-7, -8, -9 Pages VII -7, -8, -14a

2. Pates VII-9

Page VII-9

3. Page VII-14

Page VII -14

4. Page VII-16

5. Page VII-25

6. Page VII -52

7. Page VII -53

8. Page VII -54

9. Page VII -55

10. Pages VII $-55,-56$

11. Page VII -60

12. Pages VII $-62,-63$,
-70
Pages VII -53; C-4

Pages VII-16, 16 a; Resumes

Pages C-5 thru -5s

$-$

Pages Y II -55

Pages VIJ $-55,-56$ Pages Vil $-59,59 a,-60$,
$-60 a$

Pages C-5 thru -55

Date Page Revised

NRC Camment or Question

Cited Basis

$3 / 18 / 77,3 / 18 / 77,3 / 18 / 77$ Specify inspection and audit reports to be written with a given frequency; designate retention periods

Specify the Management Safety Comittee chairman and minimum review frequency

Specify review and approval requirements for changes affecting radiation and nuclear safety

,$- 3 / 18 / 77 ; ?$

pages 14 pages $3 / 18 / 77$, -

$3 / 18 / 77,3 / 18 / 77$

$-, 3 / 18 / 77$

3 pages
$3 / 8 / 77$

9 pages 14 pages
Confint type of experience in criticality analysis; include specified resumes

State criteria and associated demonstration apolicable to limited water reflection

Add bases for nuclear criticality safety of Pu systens in Appendix $C$

Reduce the minimum critical concentration of Ropused as a basis

Demonstrate applicability of a formula

ANSI N16.1-

1975

TID-7016

rans ANS,

$11 / 73$

NSE, 55 ,

$10 / 74$

$y-1272$

Demonstrate applicability of surface density method and each parameter licensed

Qual ify adequacy of concrete and distance to isolate arrays; consider interspersed moderation

Relax "stingent accounting" when moderation very small; consider effect of conerete reflection

Provide demonstrations for units and arrays of LEU and solutions; fix safe mass limits 
TABLE 3. (contd)

* NRC Question Iitle - AI-75-46 Pages Changed Date Page Revised

- -..NRC Comment or Question

Cited Basis

I11. (contd)
13. Page VII -63
Pages VIJ $-52,+54$
$3 / 18 / 77,3 / 18 / 77$
Include safety factors, val idation procedures,
14. Pages VII $-69,-70$
$-$
15. Page VII-70
$P$ age VII -70
16. Page VII-73
Page VII-73, $-73 a$
Page VII -76, -77
17. Page VII -76

\section{detamination of 1 imits of error}
Prepare criticality safety analyses in writing: confirm physical and calculational detail
$3 / 18 / 77$
$-,-$
$3 / 18 / 77$
Clarify meaning of "approved" reports
Specify safety criteria for an array of carts; mark or label all fissile material containers
Specify methods of analysis and calculation; demonstrate applicabitity of methods

IV. CRITICALITY STUDIES FOR FUEL HANDLING (APPENOIX C)

1. Page $C-1$ Page $C-1 a$ -
Page $C-2,-15,-15 a$

Page $\mathrm{C}-2$

Page $6-4$

$P$ ages $C-6,-8,-9,-10$ $+$

Page $C-12,-12 a$

7. Page $\mathrm{C}-12$

8. Page $\mathrm{C}-13$

9. Page $\mathrm{C}-15$
Page $\mathrm{C}-15$
Provide abstracts of computer codes used; validate codes; demonstrate this applicability

ANSI N16.91974

2 pages removed $3 / 18 / 77,3 / 18 / 77$

Justify factors for mass/unit area and mass/unit length; justify multiplication const.

State limitations of graphical data in which dot ted lines apply to homogeneous mixes

Confirm that all $235 \mathrm{U}$ content will be considered in combination of fissile materials

Delete request for utilization of flux-weighted solid angle method (see also III.5 above).

Include finite length dependence on two given factors

2 pages removed
$3 / 18 / 77$

Use more appropriate formulas; use the correct extrapolation length

$10-7016$,

Just if $y$ application of $Y-1272$ data for undermoderated uranium metal-water mixtures

$Y-1272$,

$2 A-1548$

$K+343$,
ORNL -2367

Justify use of calculated theoretical migration $Y-1272$ 
TABLE 3. (contd)

* MRC Question Title Al -75-46 Pages Changed Date Page Revised NRC Comment or Question

v. EDITORIAL COMENTS

\begin{tabular}{|c|c|c|c|c|}
\hline 1. & Page $V-13$ & Page $V-1,-9$ &,$- 3 / 18 / 77$ & $\begin{array}{l}\text { Identify fuel Storage } V \text { ault and other SNM areas } \\
\text { clearly }\end{array}$ \\
\hline 2. & Page $V=16$ & $P$ age $V-16$ & $\begin{array}{l}\text { deleted } \\
3 / 18 / 77\end{array}$ & Correct page references \\
\hline 3. & $P$ age $V-34$ & Page $V-34$ & $\begin{array}{l}\text { deleted } \\
3 / 18 / 77\end{array}$ & Correct page reference \\
\hline . & Page VII-52 & Page VII-5Z & $3 / 18 / 77$ & Ident if $y$ approving agency \\
\hline 5. & Page VII-68 & Page VIi-68 & - & $\begin{array}{l}\text { Update page with current Nuclear Safety Analys is } \\
\text { cover page }\end{array}$ \\
\hline & Page $\mathrm{C}-10$ & Page $6-10$ & - & Correct page reference \\
\hline
\end{tabular}

Enclosure 2 - Radiation and Process Safety

I. ORGANIZATIONAL INFORMATION

1. Page III-2 Page III-3

$3 / 18 / 77$

Supply a chart showing requested organizational structure

11. FACILITIES AND OPERATIONS AT HEADQUARTERS

1. Page $V-2,-9$ Pages $V-9,-18,-18 a$

$3 / 18 / 77,3 / 18 / 77$, - Describe Storage Vault; confirm wall thickness: demonstrate fire safety

2. Page $\forall-36$

Page $V-36$

$3 / 18 / 77$

Describe disposition of aqueous effluent

I1. FACILITIES AND OPERATIONS AT NOFL

1. Page VI-

Page $V I-14,-14 a$

$3 / 18 / 77$

Include a iayout of plutonium handling

2. Page VI -44

Pages V1-44, VII-24, -24a-, -, -

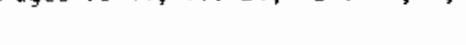

Reconcile differential pressure requirements 
TABLE 3. (contd)
* NRC Question Title
AI-75-46 Pages Changed Pages VII-120, -120 a,
$\frac{\text { Date Page Revised }}{3 / 18 / 77,3 / 18 / 77,-,-}$
NRC Comment or Question
Establish a comitment to minimizing employee exposures; minimize releases
ALARA Additions $-120 \mathrm{~b},-120 \mathrm{c}$
Cited Basis
20 CFR
20.1(c),
Guide 8.10

\section{Enclosure 4 - Fire Safety Review}

I. FACILITIES AND OPERATIONS AT NDFL

1. Page VI-4I

2. Page VI-44

3. Page VI -48

Pages VI -44, -45

Page VI -48

,-

$3 / 18 / 77$

G

11. RADIATION AND NUCLEAR SAFETY (TECHNICAL SPECIFICATIONS)

1. Page VII $-9,-14$,
$-80,-82$

2. Page WII -25

Pages VII $-25,-26$

3. Page VII -27

4. Page VII-43

Page VII -43

$3 / 18 / 77$

5. Page VII-46

Page VII $-46,-46$ a

$3 / 18 / 77,-$
Explain why and how wood is used in hot-cells; expiain how Class A fires are controlled

Explain how pyrophoric material is protected if $\mathrm{N}_{2}$ supply is cut off in a cell

$\mathrm{Cl}_{\text {arify }}$ that $\mathrm{N}_{2}$ flooding in hot cells and decont mination rom does not protect general area

Identify personnel position responsible for fire protection program

State how fires will be controlled and extinguished, once detected

Give construction details of ventilation ducts for high-level glove boxes; describe HEPA protection

Describe extent and explain "informal instruction"

Expand discussion on involvement of of $f$ site fire departments; discuss full scale drill frequency

State how information on incidents is evaluated and used 
TABLE 3. (contd)

\# NRC Question Title AI-75-46 Pages Changed Date Page Revised iv. RADIATION AND NUCLEAR SAFETY (TECHNICAL SPECIF ICATIONS)

1. Page VII-6, -7 Page VII -6, -7

2. Page VII-29

Page VII -28

3. Page VII-34

Page VII - 35
1. Emergency Plan Emergency $P$ lan

VI. MISCELLANEOUS COMMENTS

1. Bioassay Program Page VII-95 2. Page $E-6,-7 \quad P$ ages $E-6,-7$

$3 / 18 / 77,3 / 18 / 77$

\section{NRC Comment or Question}

Specify minimum frequency for inspections is annually, and not to exceed 14 months

\section{Specify alternate means to detemine liguid} levels in liquid effluent tanks

Indicate plans in monitoring coverage of fuel handling areas

$$
\begin{aligned}
& 70.24(a)(1) \\
& \text { or } 70.24(a) \\
& (2)
\end{aligned}
$$$$
10 \text { CFR }
$$

Confin that manual monitoring is continuous if performed with portable alarms

Confin periodic refresher training in radiation safety and criticality safety

Specify criteria for re-use of filters and cartridges

Supply figure on RAS Location and Coverage Perimeter - Building 004

Update and include Emergency $P$ Tan in submittal
$-$

$3 / 18 / 77,3 / 18 / 77$
Confirm that bioassay program conforms to Reg Guide 8.11

Confinm units in two tables
Cited Basis

Regulatory Guide 8.11

Enclosure 3 - ALARA Requirements
Appendix G-1 thru G-19

\section{3 pages, 16}

Provide analysis of occupational exposures for at least the past 2 years
$10 \mathrm{CFR}$ $20.1(c)$, Regulatory 
APPENDIX A

LICENSEE AND NRC PERSONNEL CONTACTED 
APPENDIX A

\section{LICENSEE AND NRC PERSONNEL CONTACTED}

NRC/NMSS, Silver Spring, Maryl and

Carter, Thomas F. $\quad(F C)$ Deputy Director, Division of Fuel Cycle and Material Safety

Crow, William T. (FCUF) Section Leader, Uranium Fue 1 Licensing Branch

Ketzlach, Norman (FCUF) Licensing Project Manager, Fuel Fabrication Plants

Nixon, William A. (FCUF) Licensing Project Manager, UF ${ }_{6}$ Production Plants

Page, Ralph G. $\quad$ (FCUF) Chief, Uranium Fuel Licensing Branch

Shum, Edward Y. S. (FCUF) Environmental Special ist

Stevenson, Robert L. (FCUF) Licensing Project Manager, Fuel Fabrication Plants

Terry, Glenn A. (FCTA) Acting Assistant Director for Operations and Technology

Thompson, William E. (FCTA) Contract Project Manager

$F C=0$ ffice of the Director, NMSS Division of Fue 1 Cycle and Material Safety FCTA $=$ Technology Assessment Branch, NMSS Division of Fuel Cycle and Material Safety

FCUF = Uranium Fuel Licensing Branch, NMSS Division of Fuel Cycle and Material Safety

NRS/SD, Rockville, Maryl and

Forscher, Fred Human Factors Branch, RES Division of Facility Operations

NRC/IE, Bethesda, Maryl and

Sly, Douglas Radiological Safety Branch, IE Division of Safeguards and Radiological Safety Inspection 
NRC/IE/Region II, At] anta, Georgia

Coryel1, Gene P.

Gibson, Albert F.

Kahle, John B.

Martin, Robert D.
Chief Inspector, Fuel Cycle Facilities

Acting Director, Division of Engineering and Technical Inspection

Inspector, Fuel Cycle Facilities, Radiation and

Process Safety

Deputy Directory, Region II IE

NRC/IE/Region III, Glen Ellyn, Illinois

Davis, A. Bert Deputy Director, Region III IE

Grant, William B. Inspector, Environmental

Peck, Charles C. Inspector, Fuel Cycle Facilities

NRC/IE/Region IV, Arlington, Texas

Collins, John T. Deputy Director, Region IV IE

Everett, Robert J. Assistant to Branch Chief, Fuel Facilities \& Material Safety Branch

NRC/IE/Region $V$, Walnut Creek, Cal if ornia

Cooley, William J. Inspector, Fuel Facilities

Thomas, Robert D. Chief, Materials Radiological Protection Section

Allied Chemical Corp., UF 6 Production Facility, Metropolis, Illinois

Cipolla, Anthony J. P1 ant Manager, Nuclear Services Division

Yates, Ron Health, Safety \& Environmental Licensing

Exxon Nuclear Company, Inc., Richl and, Washington

Hansen, Leo

Malody, Charles W.

Nilson, Roy
Staff Specialist, Criticality Safety and Licensing Manager, Licensing Compliance, Operating Facilities Manager, Corporate Licensing and Compliance 
Kerr-McGee Nuclear Corporation, Oklahoma City, Oklahoma

Dooley, Allan L. Staff Environmental Specialist

France, George M., III Staff Environmental Specialist

Marler, James $V$. Senior Staff Environmental Specialist

Shelley, William J. Vice President, Nuclear Licensing and Regulation

Rockwell International, Energy Systems Group, Canoga Park, California

Renley, Marlin E. Director, Health, Safety and Radiation Services

Schaubert, Vernon J. Manager, Nuclear Materials Management

Tuttle, Robert J. Manager, Radiation and Nuclear Saf ety

Westinghouse Electric Corp., Nuclear Fuel Division, Columbia, South Carol ina

Goodwin, Wilbur L. Manager, Regulatory Compliance

Sanders, C. F. Manager, Radiological and Environmental Engineering 

APPENDIX B

GUIDANCE AND CRITERIA USED BY LICENSING PROJECT MANAGERS 
APPENDIX B

\section{ANALYSIS OF GUIDANCE AND CRITERIA USED IN RENEWAL LICENSING}

This appendix describes the guidance and criteria used as part of the data base.

IN-HOUSE DOCUMENTS USED BY NMSS STAFF

An untitled, undated, eight page sumary was prepared by R. L. Stevenson which is used internally by NMSS. It discusses the several distinct stages in the process of issuing any new fuel cycle facility license, renewal or amendment. The summary discusses what information is needed in the application, what comprises the staff review, how questions and answers originate, how the Safety Evaluation Report is prepared, and how the license is issued. This guidance document refers to four other sources of information. Two of them are regulations ( 10 CFR 51 and 10 CFR 70), and two of them are Regulatory Guides. The "Standard Format and Content for the Health and Safety Sections of Renewal Applications for Uranium Fuel Fabrication Plants," draft Regulatory Guide FP 716-4 issued for comment in 0ctober 1980 is noted as listing the required elements that must be discussed in the license application. Further, the emergency plan is a separate submission which must meet the intent of Regulatory Guide 3.42, "Emergency Planning for Fuel Cycle Facilities and Plants Licensed Under 10 CFR Parts 50 and 70", Revision 1 issued September 1979.

A second guidance document is in the form of a note from R. L. Stevenson to L. C. Rouse and W. T. Crow, "Common Denaninators in Radiological Safety Programs (Uranium Fuel Fabrication)," December 1977. It states that the absence of accepted criteria for a radiological safety program prompted a cursory review of four licenses to determine some common practices. These 
common denominators are then listed by category, including reference to three other sources of information. 10 CFR 20 is in the formal regulatory base, but again two Regulatory Guides are listed. With only minor changes, three of four licensees committed to the bioassay program in Regulatory Guide 8.11, "Applications of Bioassay for Uranium," June 1974. It is interesting to note that License Condition 27 for AI (Rockwell International) imposed by the NRC states that the licensee's bioassay program for uranium shall conform to the provision of NRC Regulatory Guide 8.11. This is clearly a case in which regulatory guidance has been elevated to an inspectable license condition in which compliance is required. However, Regulatory Guide 8.11 is not included in Exxon or Westinghouse License conditions imposed by the NRC. Regulatory Guide 8.15, "Acceptable Programs for Respiratory Protection, "October 1976, is mentioned as becoming effective December 29,1977 . It is also included by reference in 10 CFR 20.103(c) which states that the licensee may make allowance for using respiratory protective equipment in estimating exposures of individuals to airborne radioactive material provided that such equipment is used as stipulated in Regulatory Guide 8.15 .

REFERENCES CITED IN THE ROCKWELL INTERNATIONAL SAFETY EVALUATION REPORT

There are references to 20 different regulations, guides, reports, and standards in the NMSS prepared SER. A later branch policy indicated that this SER was to be used as the model document in preparing future SERs. Numerous references are made to 10 CFR 20, 10 CFR 70 and 10 CFR 71 . Licensee documentation that was prepared as self-imposed License Conditions from AI-75-46, "Technical Information in Support of the Atomics International Application for Broad Nuclear Materials License," and AI-76-21, "Environmental Impact Assessment," are also quoted. Four annexes, attached to the license, were developed by the NRC to cover respiratory protective equipment, coping with radiation emergencies, decontaminating facilities and equipment prior to release for unrestricted use or termination of licenses, and for leak testing sealed plutonium sources. The first three annexes dealt with subjects that had been completed or were undergoing formal rulemaking procedures.

Four documents, LA-3366 Rev, LAMS-2415, TID-7016, and TID-7028, were cited as providing criteria used in checking the nuclear criticality safety of 
various situations. The implication is that each criticality safety analys is had to show that the system analyzed was at least as safe as the most conservative guidance document.

The NRC staff evaluated the submittal using recommendations contained in Regulatory Guide 3.38, "General Fire Protection Guide for Fuel Reprocessing Plants," June 1976; Regulatory Guide 3.16, "General Fire Protection Guide for Plutonium Processing and Fuel Fabrication P1ants," January 1974; and good industrial fire protection practice as contained in applicable codes and standards published by the National Fire Protection Association.

American National Standard ANSI N16.1-1975, "American National Standard for Nuclear Criticality Safety in Operations with Fissionable Materials Outside Reactors," is referenced as the source of the double contingency principle.

AI's plans for coping with emergencies were compared to the provisions and requirements of a draft Regulatory Guide, which was later issued as Regulatory Guide 3.42, "Emergency Planning for Fuel Cycle Facilities and Plants Licensed under 10 CFR Parts 50 and 70," Revision 1, September 1979. The implication is that the AI Emergency $\mathrm{Pl}$ an would have to meet the provisions and requirements of the guide to be acceptable for licensing.

The NRC-imposed License Condition 27 states in part that the licensee's bioassay program for uranium shall conform to the provision of NRC Regulatory Guide 8.11, "Applications of Bioassay for Uranium." Hence, compliance with this June 1974 guide is made an inspectable condition with compliance required.

The NRC imposed License Conditon 37 states that all calculational methods applied to the evaluation of nuclear criticality safety shall be validated in accordance with ANS 8.11/N16.9-1975, "Validation of Calculational Methods for Nuclear Criticality Safety." Hence, compliance with an ANSI Standard is made an inspectable condition with compliance required. The details of validation must therefore be provided to demonstrate the adequacy of the safety margins relative to the bias and criticality parameters and to demonstrate that the calculations embrace the range of variables to which the method will be applied. 
REFERENCES CITED IN THE EXXON NUCLEAR SAFETY EVALUATION REPORT

There are direct references to 13 different regulations, guides, and reports in the NMSS prepared SER. However, the distinction between what is required by Regulations $10 \mathrm{CFR} 20,10 \mathrm{CFR} 50$, and $10 \mathrm{CFR} 70$, and what is guidance is not clear. With two exceptions, guides and reports are used only for guidance, so compliance is not required. The first exception is Regulatory Guide 8.15, "Acceptable Programs for Respiratory Protection" which is required by 10 CFR 20.103 (c). The second exception is Annex C which was attached to the license. The NRC prepared Annex C, "Guidelines for Decontamination of Facilities and Equipment Prior to Release for Unrestricted Use or Termination of Licenses for Byproduct, Source, or Special Nuclear Material," in November 1976. Hence, it is apparent that both Regulatory Guide 8.15 and Annex C should be codified as formal regulations.

The licensee submittals of the License Application, Decormissioning Plan, and Emergency $P l$ an are noted in the SER. They contain self-imposed License Conditions, which were agreed to in negotiation with NRC/NMSS.

Three Regulatory Guides were used only to provide guidance. The double contingency policy in nuclear criticality safety was used, which is endorsed by ReguTatory Guide 3.4, Revision 1, "Nuclear Criticality Safety in Operations with Fissionable Materials Outside Reactors." An Emergency Plan was submitted which was written in accordance with Regulatory Guide 3.42, Revision 1, "Emergency Planning for Fuel Cycle Facilities and Plants Licensed Under 10 CFR Parts 50 and 70." The bioassay program for uranium is conducted in accordance with detailed provisions similar to those in Regulatory Guide 8.11, "Applications of Bioassay for Uranium." Hence, Exxon appears to use these guides for guidance as they were intended.

Five documents, AHSB (S) Handbook 1, ARH-600, DP-1014, TID-7016 Rev. 1, and T1D-7028, were cited as providing data, calculations, methods, and safety margins used in setting nuclear criticality safety 1 imits. The use of other standard references was also mentioned. 
Finally, the Waste Uranium Recovery Facility was designed to meet a variety of national and local codes and standards including the Uniform Fire Code. ANALYSIS OF CRITERIA IN THE WESTINGHOUSE SAFETY EYALUATION REPORT

The term "criteria" is treated obliquely in the SER. Aside from what is specifically stated in the regulations (10 CFR 70), the majority of procedural requirements are self imposed by the licensee. Authoritative sources of information are agreed upon and reference is made to other parts of the CFR as appropriate. Possession limits of SNM and activities concerning SNM (manufacturing of fuel) are "authorized".

The section on Nuclear Criticality Safety (VII) mentions "technical criteria that the reviewer will use to establish the criticality safety of a proposed revised or new operation" and refers to Section 2 of the 1icense application. Section VII selects 12 items which are said to be the "important criteria."

1. Double contingency policy, as "endorsed" by Regulatory Guide 3.4.

2. Mass limits are to have an "accepted" safety factor of 2.3, based on data in ARH-600, WCAP-2999, K-1019 (Rev. 5), and Handbook of Criticality Data (UKAEA, H/S Branch).

3. Dimension limits as set in I tem 2 .

4. Optimum moderation and heterogeneity are assumed.

5. Infinite reflectors assumed.

6. Credit for moderation control allawed when physically prohibited.

7. Credit given for good piping intersection design, consistent with K-1019 (Rev, 5).

8. Unknown enrichment must be assumed maximum allowed to be processed.

9. Concentration 1 imits have safety factor 2.3 .

10. Borosilicate Raschig rings used as secondary control, per Standard N16.4. 
11. K $\mathrm{K}_{\text {eff }}$ for fuel assemblies, including allowances for computation error, not to exceed 0.95 .

12. Process equipment spacing based on surface density criteria specified in 1 icense conditions. (a) Surface density criteria justified using validated KENO code and Hansen-Roach cross sections. Alternatively, spacing may be set using solid angle criterion of TID-7016 (Rev. 1), or validated KENO calculations.

What also appear to be criteria are the four bases of judgment for adequacy regarding the licensee controls to assure criticality safety:

1. History of safe plant operation

2. Demonstrated personnel qual ifications

3. The proposed (reissued) License Conditions

4. Validity of applicant's analyses.

There is a long section describing various radiation safety procedures. The criterion of acceptance for this part of the renewal application is based on:

1. Licensee's compliance history

2. Staff capability

3. License conditions

4. Program of engineering improvements to reduce airborne activity levels.

Reference is made to the Environmental Impact Appraisal, NR-FM-013, which may contain additional criteria. A copy was not available.

Condition 17 of the license requires "fulfillment of specified interim criteria on emergency plans until the information called for in 10 CFR 70.22(i) is submitted, reviewed and accepted." Annex B to the license contains the so-called criteria, which are really a list of requirements for a $\mathrm{plan}$ and procedures.

(a) Not spelled out in SER, probably means license condition 30 which refers to KENO validation and ANSI-N 16.9-1975. 
The fire safety information submitted by the licensee in his application was the Southern Building Code. The SER noted that "NRC internal criteria (not specified) for fire protection of LWR fuel fabrication plants" had been met.

Release of equipment and packages from areas of the plant are controlled by provisions in Annex $C$ to the license. These are procedural requirements and allowed surface contamination levels.

There are a number of requirements in the license conditions which imply criteria for penalties if violated:

1. ALARA committee reports

2. 100 linear fpm air velocity in hoods containing 5NM

3. Changing HEPA filter when pressure differential reaches 4 inches of water

4. Air sample exceeds concentration specified in 10 CFR 20, Appendix B, Title 1

5. Smear activities require action at set levels

6. System leak rates and explosion potential controlled

7. Ash container SNM limits

8. Refresher training and tests required

9. Safety devices to be installed on equipment

10. $H / U$ limit of 0.3 set

11. A variety of records must be kept

12. Radiological monitoring limits, analytical sensitivities, monitoring locations and bioassay action levels set

13. Decormissioning plan set.

So far as could be determined, the bases given for the license conditons did not contain or imply further criteria. Very few Regulatory Guides were referenced in the SER, although several other technical documents and regulations are referred to. 


\section{APPARENT CRITERIA USED IN ENVIRONMENTAL IMPACT ASSESSMENTS}

\section{Radiological Impacts}

The primary criteria for judging the radiological impacts of facility operations are the 10 CFR 20 air and water concentration limits for radionuclides at the site boundary, and the 40 CFR 190 limits on radiation dose to the nearest resident from facility effluents. The dose to the population within 50 miles from facility effluents is compared to the estimated population dose from natural background sources. Although it is not stated as a criterion, the inference is that a small incremental increase (fraction of a percent) over the population dose expected from natural sources is acceptable.

\section{Non-Radiological Impacts}

Airborne Effluents. In assessing the impact of non-radiological airborne effluents, a variety of different criteria are cited, depending on the pollutant and the location of the facility. The EPA Ambient Air Quality Standards serve as criteria for the impact of $\mathrm{SO}_{2}$ and $\mathrm{NO}_{\mathrm{X}}$ emissions on the area surrounding the plant. State ambient air standards are cited as criteria where applicable. If the state where the licensee's facility is located does not have a standard for a particular pollutant, another state's standard is frequently cited as a basis for comparison. Finally, the offsite concentration of a pollutant from facility effluents is sometimes compared with values from the scientific literature which have been shown to produce effects on specific plant and animal species. For pollutants which have a noxious odor at concentrations far below any limit based on toxicity, the level of detectable odor is sometimes cited as the criteria upon which a finding of "no adverse impacts" is based.

Liquid Effluents. The primary criteria for assessment of the impact of liquid effluents is the licensee's NPDES permit limits and record of compliance. The impact on bodies of water which receive liquid effluents is evaiuated by comparing the resulting concentration of the pollutants in the body of water with one or more of the following: state water quality 
standards, U.S. Public Health Service Drinking Water Standards, natural background for total hardness or B0D, National Academy of Sciences reports on Water Quality Criteria, and data from the scientific literature concerning impacts on plant or animal species of interest.

Impacts of Noise. The determination of the acceptability of noise impacts appears to be based entirely on whether the reviewer judges the noise from the facility to be excessive and readily distinguishable from the background noise in the area.

Visual Impact. The criteria for acceptability of the visual impact of a facility is a subjective determination of compatibility with its surroundings.

Social and Economic Impacts. No clear criteria were discernible. However, if the operation of the facility does not produce large fluctuations in the local area employment, and if pub1ic reaction is not strongly adverse, a finding of "acceptable" impact is likely.

Impacts of Solid and Sanitary Waste Disposal. Compliance with state and local regulations and permit requirements regarding disposal of solid wastes and sanitary wastes appears to be sufficient for a finding of no adverse impact from those activities.

Impacts of Accidents. No firm criteria were discernible. Consequences of radiological accidents are compared to the dose from natural background sources to the population. Concentrations of non-radioactive toxic materials at of $f$ site locations are compared with levels shown in scientific literature to produce various effects in plants, animals, and humans. 

APPENDIX C

COMMENTS ON DRAFT REGULATORY GUIDE, TASK FP 716-4, DIV. 3, 0ct. 1980 
March 25, 1981

Mr. Fred Forscher

Office of Standards Development

United States Nuclear Regulatory Commission

Washington, D.C. 20555

Dear Mr. Forscher:

Subject: Comments on Draft Regulatory Guide, Task FP 716-4, Div. 3, 0ct. 1980, "Standard Format and Content for the Health and Safety Sections of Renewal Applications for Uranium Fuel Fabrication Plants."

GENERAL COMMENTS

Over the years, Regulatory has received advice from inside and outside the NRC that has urged shifting the burden of licensing from the NRC to the licensee. The objective has been to lighten the paperwork burden and thereby speed the licensing process. Unfortunately, this advice has been largely counterproductive whenever it has been put into practice. To those of us who have served on both sides of the table, the reasons are now clear:

1. Whenever the granting of a license has been made dependent on analyses performed by the licensee, the effect has been to give the licensee the perspective that he is licensing himself. This tends to establish a conflict of interest. The licensee will not normally investigate matters which prima facie cast doubt on the licensability of his product or process.

2. Because the licensee has performed the most detailed safety study of his situation, he is the most knowledgeable about it. This puts him in a dominant position in any negotiation with Regulatory. Rather than speeding up the licensing process, the licensee is in a position to frustrate the NRC. He knows the regulator is less aware of potential problems, so he haggles until the regulator gives up trying to get more information. The great danger here is not that the licensee will deliberately lie or conceal known flaws in this product or process, but rather that potential risk will go unexamined.

On the other hand, if the regulator or a third party performs the key licensing analyses, then the regulator is at least as knowledgeable as the licensee. In this way the regulator remains in control. 
Mr. Fred Forscher

March 25, 1981

Page 2

3. The great bulk of licensing documentation selected for submittal by the licensee is innocuous rather than useful. This is largely recognized by both regulator and licensee, but in the mind of a licensee with an especially strong technical position, issues raised subsequent to the submittal are not relevant. (Licensees that depend heavily on third party analyses do not take this position). During the Question and Answer exchange, the licensee may adopt the position that only he knows what is "really" important for safety and all else is just paper mongering. This attitude by the licensee makes it difficult for him to view the regulator as a professional equal.

If the regulator manages the principal safety analyses, he is in a position to specify concrete information that he needs, rather than asking the licensee to "explain" or "justify" a statement or calculation.

4. Validation of licensee codes and similar safety analys is tools only give the jllusion of quality assurance in the Ticensing process. Ultimate licensing authority can only be vested in the organization with ultimate responsibility for amelioration of consequences: the government. No privately owned corporation, in this case the licensee, can be held financially accountable for damages ensuing from oversights in the licensing process. Warranties are limited, the doctrine of commercial impracticability is invoked where necessary, and insurance is finite. The threat of lawsuits, intervention, and a bad press are shrugged off; corporate officials and engineers responsible for safety consider their purview as subject to the same limitations as the financial obligations of their company. This leads to the rationalization that what they are doing for safety is already adequate and attempts by the regulator to elicit further are superfluous.

The solution to the problems created by the preception of self-licensing is to remove the perception, to acknowledge publicly the limits of corporate responsibility, and to state the precise information required for the regulator to perform the analyses. The regulator must be restored as top dog, the best informed person on the safety aspects of a given process or product.

\section{SPECIFIC COMMENTS}

1. Page IX, paragraph 2 in section entitled, "Purpose and Applicability." Be sure it is clear that the licensee's submittal (analys is) is not the basis for self licensing. It is Targely to indicate his awareness of potential hazard.

2. Part I, License Conditions, title page (no number), 1st sentence, referring to commitments. If the licensee is not legaliy bound, i.e., not punishable for failure to live up to comitments, then the commitment is not enforceable. 
Mr. Fred Forscher

March 25, 1981

Page 3

3. Chapter 2, section 2.1, page 5, "1icensee's policy." Company policies are not licensable. Conformity to the $7 \mathrm{aw}$ is licensable.

4. Section 2.8, page 7, "Audits and Inspections." Insert the word "internal" in front of "audits." It should be made clear that a part of Inspection by IE will be to see if audit findings were implemented, or if it is not worth the effort to perform internal audits.

5. Section 3.1.2 "ALARA Comnittee," page 9, 1st line of 1st paragraph. The term "commitment" is not binding as stated here. A better word would be "process."

6. Same section as comment 5, 2nd paragraph, lst line. The term "should," is it mandatory? There is a formalism regarding "shall," should," and "may" in the ANSI standards. It would be well to incorporate it in Regulatory Guides.

7. Section 4.1, pg. 12, "Special Administrative Requirements," 1st line. Change to read: "The applicant is to comply with the double contingency policy,...."

8. Same section as comment 7, 2nd paragraph, 1st line. The "criterion for a management decision . . ." should be specified by Regulatory, not left to man agement.

9. Same section as comment 8, next two paragraphs which begin "Describe..." The rest of each paragraph is the description of what is wanted. It is not useful to have the licensee restate what is prescribed in Regulatory Guides, only to acknowledge that it will be done that way.

10. Section 4.2, "technical requirements," pages 13 and 14, list of "Examples." This list should be mandatory and complete. The examples, if it is necessary to include any, should illustrate or clarify the mandated list. What seems to be lacking in the list is any alternate to the ADU process, such as direct conversion or the BNFL "dry" process. This list needs to be very specific as well as all inclusive.

11. Chapter 5, "Environmental Protection," pages 15 and 16. All paragraphs that begin "Describe" create enforcement difficulties. Regulatory must prescribe what is necessary. The licensee does not need to repeat it, only do it.

12. Section 5.1 "Effluent Control Systems," last paragraph, page 15. Change to read "Designate the positions in your organization that have responsibility for effluent control and monitoring." The rest of the existing paragraph is superfluous. It is up to Regulatory to state what is applicable. 
Mr. Fred Forscher

March 25, 1981

Page 4

13. Chapter 6, "Special Process Commitments," page 17. It is clear that NELPIA and OSHA requirements and inspections complement and even overlap NRC's areas of concern. This area of Ticensing begs for coordination.

14. Chapter 7 "Decommissioning Plan," 1st paragraph, 1st line, page 18. "Commitment " is not enforceable. Regulatory must state what is required.

15. Section 9.1. "Corporate Information," page 23. Reference to code of federal regulations should be stated at "10CFR70.22(a)(1) "Contents of Applications." It is not desirable to restate or to paraphrase the regulations. Amplification by means of acceptable examples may be usefu?.

16. Section 9.6 "Maps and Plot Plants," page 24. Add a sentence. "Indicate any unusual hazards such as a dam up river from the plant, failure of which could cause flooding at the plant site."

17. Section 9.7 "License History" page 24. This is worthless exercise. The NRC has consolidated all amendments and has kept a record of the license history. "Significant changes in corporate structure" are always taking place. Regulatory must specify that current organization charts be filed, along with names of responsible officials and where they can be reached in an emergency.

18. Section 9.8 "Changes in Procedures..", page 24, 1st paragraph and 2nd sentence. "NRC approval"? Spell out. Does this mean new application?

19. Section 11.2 "Organization Charts," page 30. See comment 17. This whole section should be one of the most active sources of correspondence.

20. Section 12.1 "Procedures" (for Radiation Protection), page 31. Won't most of this be the same as the most recent amendment to the old license in this area? How about incorporation by reference?

21. Same section as comment 20 , last sentence in section. What does Regulatory do with the "dosimetry results" and how they affect "operational planning"?

22. Section 13.1 "Occupational Exposure Analysis," page 35. The terms "Evaluate," "analyze," "provide an analysis" are vague. Regulatory should prescribe exactiy how to conduct the analys is so the information supplied is complete and to the point.

23. Section 13.2 "Measures Taken to Implement ALARA," page 35, the Ist sentence. Is the implementation of ALARA a debatable point. What is it doing here? 
Mr. Fred Forscher

March 25, 1981

Page 5

24. Section 13.3 "Bioassay Program" last Tine, page 36. The term "justified" is miscast in a regulatory context. The licensee can explain his plan or his actions, but only the NRC can justify that they meet the requirements of the law. The use of "justify" is unfortunately too compon in regulatory guides; it supports the false notion that the applicant is licensing himself.

25. Chapter 14, "Environmental Safety.." page 38, 1st paragraph. This exposure analys is ought to be prescribed for some purpose. The maximum dose may not be the most meaningful fact to be extracted from such a study. How is this information to be used? Merely compared with 10CFR 20 limits?

26. Same section as comment 25 , 2nd paragraph. The requirement is too vague to elicit a meaningful response. To what 1 imits is the result being compared? What potential hazard is being examined?

27. Section 15.2 "Preferred Approach to Design," page 39, 3rd sentence beginning "Show what. . ." It is Regulatory's responsibility to show that the applicant's design approach is adequate. The applicant can only explain what he does.

28. Section 15.4 "Analytical Methods...," page 40. "Validation of (the) analytical methods . . can only be done by Regulatory. It is not the NRC's responsibility to provide free validation service for applicant models and computer codes. Regulatory should validate its own methods and only require the applicant to submit what he has done to show a conscientious, responsible approach to the criticality safety problem. It is very dangerous for the regulator to merely accept "validation" of a code; he should get into the nitty-gritty if he really wants to depend on that computer model to support a conclusion of licensability.

29. Section 15.6 "Fixed Poisons," page 40, last sentence. It is wrong to use the word "justified." The applicant can explain his alternate procedure, but only Regulatory can justify it.

30. Section 15.7 "Structural Integrity . .," " page 41. This brief paragraph is wholly inadequate. Clearly, safety depends on proper construction and quality assurance. Why not recommend structural codes to be followed and 10 CFR50 Appendix B for the design QA.

31. Section 16.1 "Process Steps and Flowsheet," 1st paragraph, page 42. Include scrap recycling (clean scrap, "dirty" scrap, hard scrap, "green" scrap, etc.). 
Mr. Fred Forscher

March 25, 1981

Page 6

32. Chapter 17 "Accident Analys is," page 43. This is an extremely important section and requires substantial development. Classes of accidents must be defined (nuclear and non-nuclear) and criteria specified for acceptable consequences, e.g., 10CFR 20 radiation release limits not exceeded. clearly, this section relates to subjects developed in earlier sections of the submittal.

33. Same section as comment 32, 2nd paragraph. Change to read, "Discuss the means for coping with possible flood, explosion or fire." Do not give applicant option to say something is unnecessary. It only handcuffs the reviewer and leads to side arguments, distracting from the main issues.

34. Append ix A "Safety Margins. . .," page 45. It should be made clear that these methods are those used by the reviewers to establish the licensability of the process. Whether the applicant uses these methods is irrelevant. We do not want to set the stage for a hassle over whether or not the reviewer followed the rules correctly. The reviewer's calculations are part of the public record. The argument should be over the reasonableness of the rules themselves. The results of such negotiation should lead to changes in the Reg. Guide.

Sincerely,

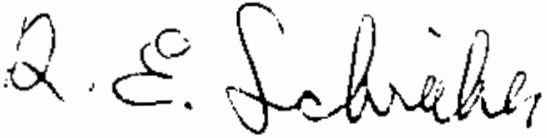

R. E. Schreiber

RES:bjb

cc: Mr. William Thompson

Technology Assessment Branch

Fue T Cycle and Material Safety, NMSS

Nuclear Regulatory Commission

Washington, D.C. 20555 
APPENDIX D

QUESTIONS AND COMMENTS ON CONSOLIDATED RENEWAL APPLICATION, WEST INGHOUSE ELECTRIC CORPORATION, COLUMB IA, S.C., DOCKET NO. 70-1151, DECEMBER 30, 1976 
APPENDIX D

QUESTIONS AND COMMENTS ON CONSOLIDATED RENEWAL APPLICATION, WESTINGHOUSE ELECTRIC CORPORATION, COLUMBIA, S.C., DOCKET NO. 70-1151, DECEMBER 30, 1976

I. CONCERNING SAFETY DEMONSTRATION, SECTION 1

1. Page 16, para. 1.3.3 - Describe the practices followed in outside storage of low-level contaminated solid waste, including packaging requirements and acceptable contamination levels.

Response: Not traceable (NT); this page changed since 1977.

2. Page 24 , second para, under para. 1.3.7 - It should be made clear by additions to the text that the quantities of SNM in the accumulations of waste are subject to check by gamma scan.

Response: Accepted changed page (ACP)

3. Page 25, para. 1.3.8, Fire Protection - Please provide evidence of insurability of the Columbia plant for liability insurance with one of the major nuclear insurance pools and evidence that the building meets the Southern Building Code, as indicated during R. L. Stevenson's visit on March 17, 1977.

Response: Insurability evidence provided $8 / 19 / 77$ (NELPIA letter $12 / 27 / 76$ )

4. Page 44, para 1.7 - A more complete, updated description should be provided of the manuals, including how the manuals relate to daily operations, that are followed for safety matters, such as the Health Physics Manual, the R\&E Services Manual, and Pl ant Safety Manual.

Response: ACP

5. Page 60, para, 1.8.1.2 - We are not aware of recent data to conf irm the inferred low k-infinity value for oxide of $5 \%$ maximum enrichment at less than $0.5 \mathrm{H} / \mathrm{U}$ value. For $4 \%$ oxide, on the basis of directly relevant calculations, Welfare proposed a maximum $0.45 \mathrm{H} / \mathrm{U}$ atomic ratio in "Evaluation 
of Very Low Moderation LOW-Enrichment $\mathrm{UO}_{2}$ Systems," in ANS Transactions Vol, 19, page 201 (1974). Please confinm that the $0.5 \mathrm{H} / \mathrm{U}$ limit will be reduced, consistent with your letter of December 14,1976, concerning the limits with the 5\% enriched oxide.

Response: ACP

6. Page 65 , end of top para. - (a) The system to which the 0.98 keff applies should be identified and justification provided, considering the uncertainties in the calculations, the limited range of systems explored, and the broadness of the conclusions. Alternatively, a lower $k_{\text {eff }}$ criterion could be used and corresponding justification presented

Response: ACP

(b) It should be confirmed that the 12-inch spacing between cylinders and floor is an integral part of the surface density criteria (with appropriate additions to Section 2) or justification provided for omission from the criteria.

Response: Not specifically traceable

7. Page 68 - Criteria for excluding interaction as a consideration should note that moderation control must be maintained under normal and accident or unusual conditions.

Response: $A C P$

8. Page 69 - (a) The text should include a description or reference to the procedures for evaluating interaction between units which are susceptible to moderation from a single occurrence, such as fire fighting. (b) If moderation of stored fuel assemblies, as by fire fighting, is not analyzed, the analyses should demonstrate that such moderation cannot occur. Response: (10/7/77) Text apparently not changed; statements made that credible conditions involve para. 2.3..2.2d; fire fighting with hydrogenous materials not permitted..

9. Page 72 - (a) It is stated that changes are assigned to the Materials Department for necessary engineering prior to adoption but the description of the Materials Department (pages 33, 254) does not include 
responsibility for engineering. Please explain and update the text.

(b) Why does the Criticality Engineer get involved in the radiation safety requirements instead of a health physicist from Mr. Sanders' group? The text should be augmented with a description of nuclear criticality safety review procedures.

Response: ACP

10. Page 74, para. 1.8.3.1 - What qualifications form the basis for the decisions by the Manager, Safety, to relax safety margins? Please incorporate these qualifications into Section 2.

Response: Not traceable (NT). Accepted change pages (ACP)?

11. Page 80 - (1) The discussion of accidental introduction of $5 \%$ enriched material is based on solution systems. How would such an error be detected before $\mathrm{UO}_{2}$ formation? (b) It should be made clear that no hot $\mathrm{UF}_{6}$ cylinder will be moved unless the valve cover is on. (c) What is the rationale for not including remotely operable devices for closing the $\mathrm{UF}_{6} c y l$ inder valves as part of the engineered safety of the vaporization equipment?

Response: (11c) (8/19/77) Design problem being investigated

12. Page 9l - What is the basis for the nuclear criticality safety of these off-gas filters under normal and abnormal conditions?

Response: NT ACP?

13. Page 92 - How was the reflector effectiveness of concrete allowed for in setting the slab thickness of the scrubber reservoir?

Response: NT ACP?

14. Page 93, 3rd line - The text was revised to delete reference to dryness analysis. Is the product dryness one of the product specifications and if not, what is the justification for using dryness as a basis in subsequent nuclear criticality safety controls?

Response: NT ACP?

15. Page 96 - What is the geometry and size of the cartridge prefilter? Response: NT ACP? 
16. Page 97 - Please provide a revised page giving an updated description of the controls on the ion exchange operation.

Response: (8/19/77) Claimed that submittal contained approved amendment

17. Page 99, para. 1.9.1.9 - Please supplement the text to describe how the proper functioning of the in-line waste monitors is confirmed.

Response: NT ACP?

18. Page 101 - The quoted $9-10 \mathrm{pH}$ violates the maximum $7.0 \mathrm{pH}$ given in Section 3.1(1) of the ANSI N16.4-1971 standard. Please justify this exception to the standard.

Response: (8/19/77) Application changed to state that Raschig rings are supplementary criticality control. Inspection made to assure no degradation due to $\mathrm{pH}$ change.

19. Page 106 - The simplified approach to $k_{\text {eff }}$ was discredited for these materials subsequent to the application of 1969, as implied by the data in Figure 2.3.2.12 on page 230. The $k_{\text {eff }}$ calculation should be corrected and fulfullment of the solid angle criterion demonstrated.

Response: (12/30/77) Solid angle calculations submitted.

20. Page 111 - Additional information should be provided giving the justification for not analyzing the effects of interspersed moderation on the dry storage, as from fire fighting operations.

Response: NT ACP?

21. Page 112, lines 4-6 - What is the basis for the claim of isolation by concrete between columns of $\mathrm{UO}_{2}$ containers? Please conf irm that the individual containers meet the safe diameter limit and that no safety conclusions were drawn from the fact that a vertical column of the containers has a volume equivalent to that of a continuous cylinder having a diameter of 9.5 inches.

Response: (12/30/77) Criticality saf ety evaluation submitted.

22. Page 114 , second para. - Please describe the administrative controls that are used in limiting the SNM accumulations in the filters.

Response: NT ACP? 
23. Page 117, Concerning multiply-stacked slabs - Please describe how it was determined that the possible accumulation of water, i.e., anount of retention, would be sufficiently low to ensure subcriticality?

Response: Calculation $(10 / 7 / 77)$ shows atom ratio $(H / U)=0.472$ if standing water gets into stacked pellet trays (tipped to retain water).

24. Page 119, 3rd line - The word "normally" should be deleted. Response: NT Accepted?

25. Page 126 - (a) The minimum frequency of alarm tests and records of tests should be described and incorporated in the requirements in Section 2. (b) Please explain the reason for allowing the steam flow to continue on automatic shutdown.

Response: NT ACP?

26. Page 157. The text concerning 10 CFR 70.24 should be updated. Response: NT accepted?

27. Page 162 , bottom 3 lines - The washing machine capacity was changed from 20 to $130 \mathrm{lb}$, the 1 ist of items to be handled was expanded, and the weight limit changed to net weight. How are conservative tare weights established for the range of materials handled?

Response: ACP

28. Page 167 - The practice of analyzing the effluent gases for oxygen prior to introduction of hydrogen has apparently been dropped. Please justify the safety of the revised procedure.

Response: Historical adequacy of $\mathrm{N}_{2}$ purge is reason $\mathrm{O}_{2}$ analysis dropped in DCFB process (prior to $\mathrm{H}_{2}$ introduction) (8/19/81).

29. Page 168 - How is it concluded that significant steam condensation and fissile material accumulation are not credible, e.g., as a consequence of human error or valve leakage, following an emergency shutdown? What checks are made of the leaktightness of the normally closed type valves? Response: ACP

30. Page 190, second para. - The referenced para. 1.3.7 does not include storage criteria for ash and hence the criteria need to be defined.

Response: ACP 
II. CONCERNING SPECIF ICATIONS, SECTIONS 2 AND 3

Note that foregoing questions $6(b), 10,25(a)$ relate to Section 2 .

32. General - The proposed license conditions should be reviewed and words deleted that make the requirements less certain or specific, such as "primary" on the first line and "primarily" on the fifth line of para. 2.1.2 on page 202, "approximately" on the sixth line of page 255, and "normally" on line 3 of page 262 .

Response: $A C P$

33. Pages 201-202 - The definitions should include a definition of "fraction critical," which should accord with Section 1, pages 61-62. Oefinitions should also be provided for "controlled area," "uncontrolled," and "restricted area."

Response: $A C P$

34. Page 203, para. 2.1.1(b) - Many calculations have been reported during the past several years that indicate potentially significant neutron transmission through concrete in thicknesses up to 12 inches. References to 8 or 12 inches of concrete as "isolator" should be deleted.

Response: $A C P$

35. Page 203, para. 2.1.2 - The safety demonstration has not covered a wide range of uranium compounds as feed materials and thus the words, "Examples of" should be deleted from the top line.

Response: $A C P$

36. Page 204, fourth 1 ine up - What is the meaning of "fissile $\mathrm{PuO}_{2}$ "? Response: ACP

37. Page 205, Section 2.2 - This section should include a specification of the required minimum functioning instrumentation and equipment, including tests, frequency of tests and records of test, sufficient to permit safe operation of the DCFB equipment. This section should note that operating procedures for the DCFB equipment shall include the limiting safe parameter values for the equipment.

Response: ACP 213, 213.1 
38. Page 20, para. 2.2.5 - The words "and operated" should be inserted after "designed".

Response: $A C P$

39. Page 208, para. 2.2.5 (top para.) - Please add the specification, for open faced hoods or other open-faced enclosures, of a minimum $100 \mathrm{lfm}$ air flow, a minimum inspection frequency for inlet velocity of once per month, and the corrective actions to be taken and documentation when the inlet velocity requirement is not met.

Response: $A C P$

40. Page 208, third para. - The paragraph should be modified to add "and operated" after "designed", to require a minimum differential pressure of more reasonable magnitude $\left(0.10\right.$ inch $\left.\mathrm{H}_{2} 0\right)$, to add a requirement for instrumentation on each box to show the differential pressure, and to set a minimum frequency of once per month for checks of the differential pressure.

Response: $A C P$

41. Page 209, top para. - Concerning the possible use of filters of less than 99.97\% rated efficiency, please state the specific criteria that will be used in determining that lower rated filters will be sufficiently effective.

Response: NT

42. Page 209, second para. - Please state the actions to be taken at specified differential pressure values.

Response: NT

43. Page 209 , third para. - The reference should be changed to Regulatory Guide 3.2 instead of UL -586 .

Response: NT

44. Page 209, para 2.2.5 - There should be a requirement to sample the exhaust from the recirculating air cleanup systems, including the local exhaust units for equipment and hoods, with action points and actions to be taken. Alterntively, justification could be provided for use of other defined controls.

Response: NT 
45. Page 209, para 2.2.6 - The text should include a statement of the minimum frequency at which the representativeness of the air sampling will be checked.

Response: NT

46. Page 210, para. 2.2.8 - Justification should be provided for the $1 \mathrm{Cj} / \mathrm{lb}$ general cutoff value or for an alternative if one is proposed.

Response: ACP

47. Page 210, para. 2.2.9 - The reference to 10 CFR 70.24 should be more specific, i.e., whether conformance to $70.24(\mathrm{a})(1)$ or $70.24(\mathrm{a})(2)$ is intended.

Response: ACP

48. Page 210, para. 2.2.9 - It should be stated that emergency power is connected to the criticality alarms.

Response: ACP

49. Page 211, para. 2.2.10 - Please confirm, and add a statement here, that the designs will be reviewed by a Civil Engineer or registered professional engineer.

Response: ACP

50. Page 212, third sentence - The location of the pressure relief valve and liquid level detector should be corrected.

Response: $A C P$

51. Page 213, para. 2.3.1 - Please add a requirement that the regenerations be logged.

Response: $A C P$

52. Page 214, para. 2.3.2.1 - (a) The first paragraph needs clarification, including definitions of terms. (b) It should be noted that material of unknown enrichment shall be handled as if it were at the maximum enrichment credible under the circumstances.

Response: $A C P$

53. Page 222, Nuclear Interaction Criteria - (a) The requirements should include the controls to ensure that fissile material in movement does not enter into the assigned spacing area of other fissile material. (b) It 
should be made clear how the operator "on the floor" knows what the areas are. (c) Please include the arrangements for maintenance of a master $\mathrm{pl}$ an and marking system (or alternate controls) according with currently approved equipment layouts.

Response: (12/30/77) Refers to telecon $12 / 9$ between R. L. Stevenson and $W$. Goodwin. Operator Training is implicit in response provided $10 / 7$ as revised pg 232.1 of transmittal. Westinghouse felt this was sufficient.

54. Page 223, Figure 2.3.2.6 and subsequent figures - To reduce the probability of misreading of limit values, please delete the critical values from these tables.

Response: ACP

55. Page 225, Figure 2.3.2.8 - A bare critical slab thickness of 10.6 inches is quoted for $3 \%$ enriched homogeneous oxide whereas Figure III.B.5-4 of ARH-600 gives a value of 10 inches. Please justify use of the criterion based on the higher value or revise the tabulated value.

Response: Bare critical values removed from $F$ igures 2.3.2.6 and 2.3.2.8 in 10/7/77 submittal. Westinghouse also noted that double batching was precluded by engineering/administrative controls $(12 / 30 / 77)$.

56. Page 226, Figure 2.3.2.9 - The safety margins provided by the use of this graph are considered insufficient and it is recommended that the criterion $\mathrm{ts} / \mathrm{tc}$ be 1 imited to 0.25 for geometry limited units. This recormendation is based on a couple of test calculations, which are summarized below, and the following:

a. The smeared thickness criterion is based on water reflected slabs but the surface density criteria are applied to systems that may be reflected by concrete.

b. The surface density critera do not impose limits on the spacing of array units from the reflectors.

c. The surface density criteria are applied to a variety of geometric forms whereas the major part of the backup KENO analyses were made for square arrays of cylinders. 
d. The quoted limiting $k_{\text {eff }}$ criterion - see comment concerning page 65 - is too high and does not allow for effects of possible maloperations such as were identified in the enclosure to the AEC letter to Westinghouse dated May 8, 1973.

A calculation was made of the $k_{\text {eff }}$ of a concrete-reflected $10 \times 10 \times 1$ array for parallel slabs of $\mathrm{U}(4) \mathrm{O}_{2}-\mathrm{H}_{2} \mathrm{O}$ at $2 \mathrm{gm} \mathrm{U} / \mathrm{cm}^{3}$ concentration. The slabs were $8 \mathrm{ft}$ by $10 \mathrm{ft}$ by 4.8 inches thick, spaced at $7.96 \mathrm{ft}$ center-to-center (in the direction perpendicular to the large slab faces) to meet the criterion in Figure 2.3.2.9 based on a fraction critical of 0.2 from Figure 2.3.2.12. The calculation was made using KENO and Knightmodified Hansen-Roach cross sections and the $k_{\text {eff }}$ was $0.9636 \pm 0.00508$ (one sigma).

A calculation was made for an array of cylinders of the same composition used in the foregoing case. A concrete-reflected $1000 \times 1000 \times 1$ square array of 8.08-inch-diameter cylinders of $25 \mathrm{H} / \mathrm{D}$ was found to have a keff of 0.998 at a center-to-center spacing of $5.41 \mathrm{ft}$. This array meets the surface density criteria for geometry 1 imited units since the unit fraction critical is below 0.2 and the $\mathrm{ts} / \mathrm{tc}$ is below the allowed 0.484 .

Response: ACP

57. Page 230, Figure 2.3.2.12 - This figure, quoted on page 228, gives $k_{\text {eff }}$ values for units above 0.4 fraction critical that exceed the limiting $k_{\text {eff }}$ criterion (0.8) of the solid angle method. The failure to meet solid angle criteria when the surface density criteria are not met would imply that unit reactivities are too high to apply the models. Please confirm that the limiting $k_{\text {eff }}$ criterion will meet and change the test accordingly.

Response: $\mathrm{NT}$

58. Page 231, para. C.6 - This paragraph should be further clarified as to the criteria to be met on the vertical plane and examples of the application of the criteria (Section 1) should be provided.

Response: Application changed and calculated example done (10/7/77). 
59. Page 231, para. d - The enumerated considerations should include some reference to appropriate controls over fire fighting or other water sources. Response: ACP

60. Page 232, para. 2.3.2.2.g - Since the MPV's for plutonium bearing subcrits are limited to those in Figure 2.3.2.5, reference to the 0.3 maximum fraction critical appears to be unnecessary. If limits other than those in Figure 2.3.2.5 are to be authorized, an example should be given as to how fraction critical will be determined.

Response: NT ACP?

61. Page 234 - Concerning the administrative procedures to control changes:

a. How are plant operations supervisors and maintenance supervisors made aware of the requirement that changes be reviewed by Radiological \& Environmental Services (RES)?

b. Who inspects the installed equipment for conformance with nuclear criticality safety and radiation safety requirements?

c. What formal procedure is used to ensure that changes in process, equipment or procedures are reviewed for both radiation and nuclear criticality safety and what signature approvals are required for operating procedures, design drawings, and confirmation of correctness of installation?

d. How is it ensured that plant procedures relative to safety are maintained up-to-date as equipment or process changes are made?

The responses to the foregoing should be incorporated in Section 2. Response: (a) Not answered (b) not answered (c) reference made to procedures RES -202 and 300 (d) reference made to revised application para. 2.3.2.2

62. Page 234, para. 2.3.2.3 - The required training and experience for the position responsible for verifying nuclear criticality safety analyses should be incorporated here, either specifically or by reference to another paragraph in Section 2.

Response: $A C P$ 
63. Page 234, second para. under para. 2.3.2.3 - Please add the positions in the organization to which the biweekly inspection reports are addressed and the procedures for ensuring followup corrective action on items to be corrected.

Response: ACP

64. Page 235 , second para. - This paragraph appears to require the approval of the radiation protection function for any operation not covered by a routine operating procedure. We will interpret the requirement in this manner unless further clarifying changes in the text are provided. The paragraph should require maintenance of records of the approvals.

Response: NT

65. Page 235, Emergency Procedures - The plans for coping with radiological emergencies should be updated to demonstrate conformance with the revised requirement in Part 70 that became effective March 31, 1977.

Response: $A C P$

66. Page 251, para. 3.1.1 - This text lacks specificity as regards participation by Radiological and Environmental Services (RES) in the review of procedures and should be revised to clarify the role of RES in approving procedures. Also, the requirement should be added that records of such approvals will be maintained.

Response: NT

67. Page 252-253 - The responsibilities of Radiological and Environmental Services should be stated more explicitly. We recommend inclusion of the following:

The Radiological and Environmental Services component has several specific responsibilities:

a. review and approval of procedures which involve use of storage of SNM

b. review and approval of design drawings

c. audits of all licensed activities

d. training and monitoring training effectiveness in:

1) health physics 
2) nuclear criticality safety, and

3) emergency planning

e. conduct and review of nuclear criticality safety analyses

f. review of changes for health physics aspects

g. review and approval of non-routine work orders, routine work orders, and radiation and work permits

h. scanning of waste

i. routine surveillance of operations. Response: $A C P$

68. Page 253 - Applicable offsite exposures are not given in the general reference to Title 10. The wording with respect to the maximum credible accident (MCA) should be revised to require NRC review and approval of process changes which result in MCA's in excess of those previously evaluated.

\section{Response: $A C P$}

69. Page 254-255, ALARA Committee - The objective of the committee should be augmented to indicate more clearly their determining (1) if there are any upward trends developing in personnel exposures for identifiable categories of workers or types of operations or effluent releases, (2) if exposures and releases might be lowered in accordance with the concept of as low as reasonably achievable, and (3) if equipment for effluent and exposure control is being properly used, maintained and inspected.

Paragraph 20.1(c) of 10 CFR Part 20 states, in part, that licensees should make every reasonable effort to maintain radiation exposure as far below the limits specified in that part as reasonably achievable. Regulatory Guide 8.10, copy enclosed, describes the basic operating philosophy and administrative practices that a licensee should follow to keep occupational radiation exposures as low as reasonably achievable. Incorporating the intent of Regulatory Guide 8.10 in your renewal application will require the following:

a. Provision, as an appendix or addendum to your application, of an analys is of occupational exposures (external and internal) covering 
at least the past two years of plant operations for each plant area and type of operation performed. The analys is should identify the sources and locations where most exposures occurred, as related to job categories and work activites. Any trends in exposures that can be identifed should be discussed. Abnormal occurrences should be reviewed and categorized, considering such aspects as frequency, operations being performed, and the magnitude of resulting exposure. The analysis of internal exposures should consider air sampling data, as well as bioassay data (including in vivo counting). The analysis should conclude with a description of any steps or measures taken to reduce employee exposure, the effectiveness of these measures, and any additional actions planned.

b. With Regulatory Guide 8.10 as a basis, inclusion in Section 3 of appropriate conditions and specifications to establish a commitment to minimize employee exposures. We consider the ALARA Committee to be a clear indication of your commitment. In addition to the philosophy of Guide 8.10 , the proposed conditions and specifications in Sections 2 and 3 should reflect as may be appropriate, the results of the analys is requested in Item 1 above.

Paragraph 20.1 (c) of Part 20 also requires 1 icensees to make every reasonable effort to maintain releases of radioactive materials in effluents to unrestricted areas as low as reasonably achievable. In a manner comparable to that requested above for personnel exposures, provide an analysis of radioactive releases (concentrations and quantities) from the plant during the past year. Section 3 should also contain specific conditions and specifications to establish a commitment to maintain radioactive material releases to as low as reasonably achievable. In this regard, we believe that all points of release should be continuously and representatively sampled for routine periodic analysis. (A representative sample should be collected and analyzed before any batch release of liquid effluents.) Please provide your justification for any deviation from this position.

Response: (10/7/77) Summaries of historical radiation protection data submitted. 
70. Concerning Reviews of Safety Administration, Policy, and Major Decisions Most licensees include high level reviews of safety administration and policy in the license application as part of the safety system. Section 2 or 3 should be augmented with the requirements for the safety system overviews, giving the type and frequency of reviews and the qualifications of the reviewers of the safety decisions, policies and practices of RES. It is recognized that RES has the prime responsibility for day-to-day safety decisions, but Westinghouse's procedure for confirming the overall quality of these decisions is appropriately a part of the license.

Response: Cancelled, according to Westinghouse letter 10/7/77.

71. Page 255 - It should be confirmed that the "Manager of the Radiation Protection Component" means the Manager, Radiological and Environmental Services.

Response: $\mathrm{ACP}$

72. Page 257 - (a) Please include a stated minimum frequency for the refresher training. (b) The procedures for measuring the effectiveness of the training should be provided, either here or in Section 1.

Response: $A C P$

73. Page 259, para. 3.2.1 - The text should specify that records of calibrations will be maintained for a specified period.

Response: $A C P$

74. Page 262 , para. 3.2.2 - The response to the high air sample results should include both increased sampling and investigation. Please specify action levels and actions that will be taken, up to and including equipment shutdown.

Response: $\mathrm{ACP}$

75. Page 262, para. 3.2.2 - Please provide justification for not following the requirements of Regulatory Guide 8.11 and describe the alternative here. In addition to fulfilling the requirements of R.G. 8.11, or a justified specified equivalent, the text should require performance of an in-vivo count for uranium on each new employee who has previously handled SNM. 
Response: (8/19/77) Discussion of urine counting: not considered reliable, air monitoring preferred.

76. Pages 264 and 265 - The instrument sensitivity and release levels stated for contaminated items should be augmented with action levels indicating the actions to be taken at specified contamination levels. There should be a specification of actions to be taken within a specific time if guides in Table 3.2.4.1 are exceeded. There should be specified minimum smear survey frequency in process, step-off, eating and clean areas.

Response: $A C P$

77. Page 266 - (a) Why doesn't the title of the component agree with Figure 1.4.1.1? (b) Required qualifications of education, training and experience shouid be stated for the Manager, Health Physics, and the Criticality Engineer. (c) The experience of the component manager should include at least a year of directly relevant nuclear criticality analysis.

Response: ACP

78. Page 267, last para. under Section 3.3.3 - What are the assigned responsibilities of the position with the prescribed qualifications? If this position has responsibility for nuclear criticality analysis or reviews, the qualifications should include at least one year of nuclear criticality analys is.

Response: ACP

79. Page 279, para. 4.4.2 - The proposed revised wording no longer conforms to $71.7(b)(5)$ of Part 71 . Considering that the fissile material in eight cuboidal boxes might come together with a possible $2800 \mathrm{gm}$. U-235 inventory, how is subcriticality ensured without some requirement on the $f$ issile material distribution with in the boxes?

Response: $A C P$

80. Page 280 , para, 4.6(2) - Further clarification of this subparagraph is needed. If the fuel in movement outside of the container is to exceed one fuel assembly, a nuclear criticality safety analysis should be provided.

Response: ACP 
III. COMMENTS OERIVEO FROM ENVIRONMENTAL IMPACT APPRAISAL, NR-FM-013

81. Concerning Stack Effluents - (a) What are the action levels for both radiological and non-radiological effluents? (b) What are the required responses (actions) to be taken? The answers to the foregoing questions and to item 83 below should be incorporated into the requirements of Section 2 by addition of appropriate pages.

Response: NT

The following are anticipated requests or conditions in the renewal license from the Environmental Impact Appraisal, NR-FM-013, pages 3-17, 4-14, 5-4, and 5-5.

82. Page $3-17$, para. 3.3.3.2 of EIA - Westinghouse shou1d submit plans for permanent disposition of the $\mathrm{CaF}_{2}$ in the waste lagoons.

Response: NT

83. Page 4-14, para. 4.2.3 of EIA - Westinghouse should set action levels for protection of the groundwater.

Response: (8/19/77) Discussion points out that paragraph 4.2.3 refers to upstream analysis of $\mathrm{NH}_{3} \& \mathrm{~F}$ in well water, so action levels are not appropriate. Downstream action levels given.

84. Page 5-4 of ElA, para. 5.2.5.1 Atmospheric monitoring - Amnonia and fluorides in process-gas effluent stacks and at the site boundary shall be measured quarterly by the methods presently in use. The spring and fall season samples shall be collected at the same time vegetation is sampled. The atmospheric sampling program shall be operational before further increase in plant capacity so that variation in values from current production will be established.

Response: (10/7/77) Westinghouse - Yes

85. Page 5-4 of EIA, para, 5.2.5.2 Surface waters - Sunset Lake and Mill Creek shall be monitored monthly for ammonia, fluorides, and $\mathrm{pH}$ at the five stations identified in para. 5.2.2.2 of the EIA. The Congaree River shall be monitored monthly for ammonia, fluoride, $\mathrm{pH}, \mathrm{BOO}_{5}$ and total suspended solids. The monitoring stations on the Congaree River shall be (1) 1500 yd 
above the NFCS discharge, (2) directly at the outfall of the discharge, (3) 1500 yd below the discharge, and (4) 1500 yd below the mouth of Mill Creek. There shall be a monthly monitoring program for residual chlorine (in sanitary effluent) at the outfall of the discharge.

Response: (8/19/77) Westinghouse will monitor for $\mathrm{F} \& \mathrm{NH}_{3} \& \mathrm{pH}$. Not for $\mathrm{BOD}_{5}$ and suspended solids. $\mathrm{Cl}$ in sanitary discharge will be monitored. R. L. Stevenson notes: ORNL, Kathy Oakes, says location of samples 10x river width. Westinghouse answers not acceptable. Oakes phone number given to Westinghouse.

86. Page 5-5 of EIA, para. 5.2.5.3 Groundwater - The three onsite wells shall be monitored monthly for fluoride, amonia, $\mathrm{pH}$ and fecal coliform count. Response: (8/19/77) Westinghouse will not check wells for fecal coliform because the sanitary plant discharge meets requirements.

87. Page 5-5 of EIA, para, 5.2.5.4 Biota - Samples from forage plants in pastures or croplands at the site shall be taken in May and September and analyzed for fluoride content. The same plant species shall be analyzed each time and the sampling program shall be operational before further increases in production capacity so that background value variation may be established.

Response: (8/19/77) Westinghouse-Yes 


\section{OISTRIBIT ION}

No. of

Copies

\section{$\underline{\text { OFFSITE }}$}

A. A. Churm

DOE Chicago Patent Group

9800 South Cass Avenue

Argonne, Il. 60439

U.S. Nuclear Regulatory Commission

Division of Technical Information and Document Control

7920 Norfolk Avenue

Bethesda, MD 20014

W. E. Thompson

Nuclear Regulatory Comonission

Office of Nuclear Material Safety and Safeguards

Washington, DC 20555
No. of

Copies

2 DOE Technical Information Center

ONSITE

50 Pacific Northwest Laboratory

D. W. Brite

R. G. Clark (37)

L. C. Davenport

J. D. Jamison

R. E. Schreiber

R. J. Sorenson

E. C. Watson

Technical Information (5)

Publishing Coordination (2) 



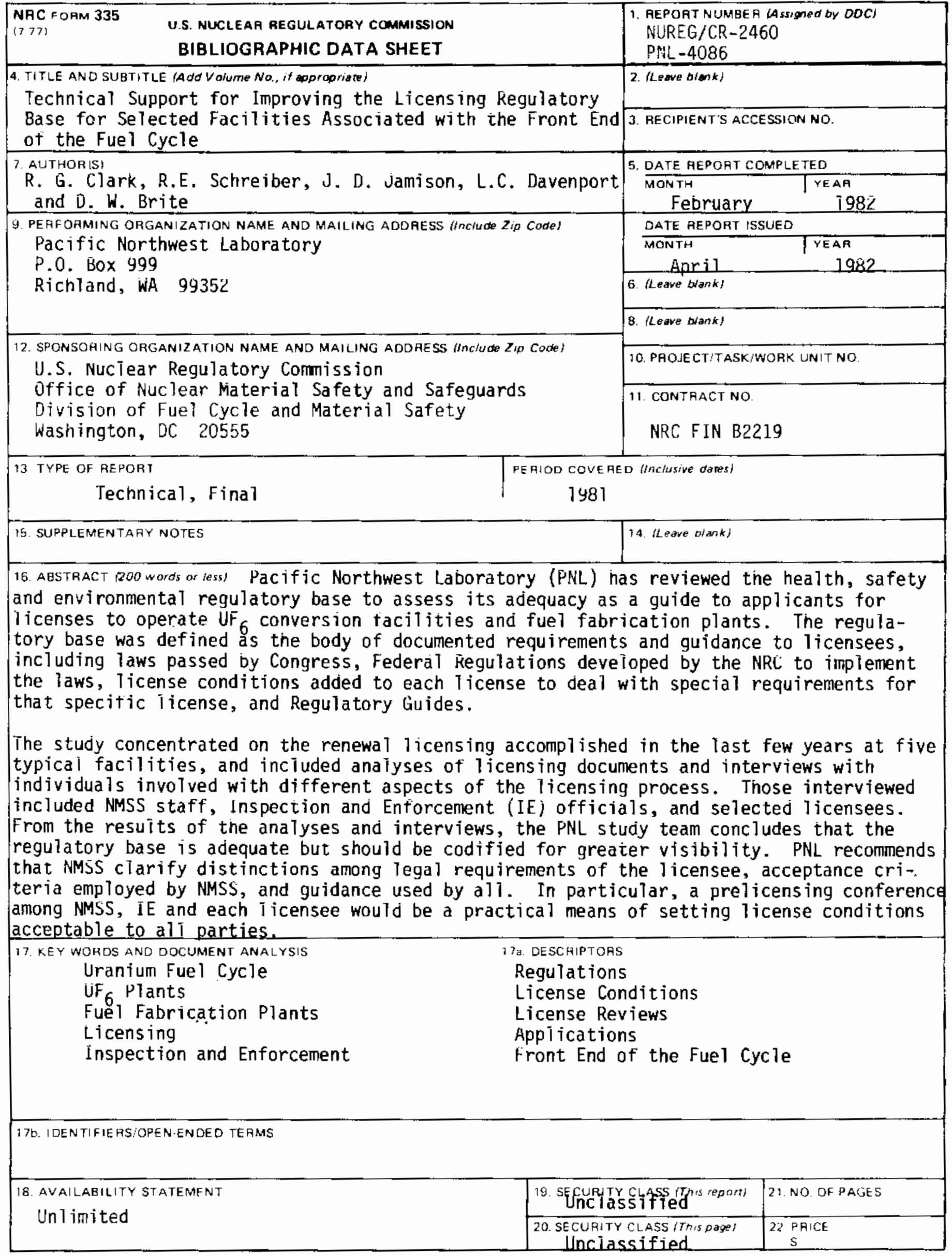


